\title{
Gestão estratégica de pessoas no Legislativo Federal brasileiro: condições para a implementação
}

\author{
Felipe Guimarães Côrtes ${ }^{1}$ \\ Pedro Paulo Murce Meneses ${ }^{2}$ \\ ${ }^{1}$ Instituto Brasiliense de Direito Público / Escola de Administração de Brasília, Brasília / DF — Brasil \\ ${ }^{2}$ Universidade de Brasília / Programa de Pós-Graduação em Administração, Brasília / DF — Brasil
}

Esta pesquisa objetivou identificar aspectos interferentes na implementação da gestão estratégica de pessoas (GEP) nos órgãos do Poder Legislativo Federal brasileiro e as possíveis relações entre eles. Por meio de entrevistas e grupos focais realizados com 16 gestores do Senado Federal (SF) e da Câmara dos Deputados (CD) foram identificados 21 aspectos interferentes, divididos em categorias institucionais, políticas, organizacionais e setoriais, bem como foram elaborados modelos teórico-empíricos das influências exercidas por cada um dos aspectos sobre os demais, a partir do que se concluiu que os condicionantes mais significativos teriam natureza política, pois definiriam os recursos e a autonomia disponíveis para as unidades de gestão de pessoas (GP) conduzirem o processo de implementação.

Palavras-chave: gestão estratégica de pessoas; gestão de pessoas na administração pública; gestão de pessoas no Poder Legislativo.

\section{Gestión estratégica de personas en el Legislativo Federal brasileño: condiciones para la implementación}

Esta investigación se propuso identificar aspectos interferentes en la implementación de la gestión estratégica de personas en los órganos del Legislativo Federal brasileño y las posibles relaciones entre ellos. Por medio de entrevistas y grupos focales realizados con 16 gestores del Senado Federal y de la Cámara de Diputados, se identificaron 21 aspectos interferentes, divididos en categorías institucionales, políticas, organizativas y sectoriales, así como se elaboraron modelos teórico-empíricos de las influencias ejercidas por cada uno de los aspectos sobre los demás, a partir de lo que se concluyó que los condicionantes más significativos tendrían naturaleza política, pues definirían los recursos y la autonomía disponibles para que las unidades de gestión de personas conduzcan el proceso de implementación.

Palabras clave: gestión estratégica de personas; gestión de personas en la administración pública; gestión de personas en el Poder Legislativo.

\section{Strategic human resource management in the Brazilian federal legislative: conditions for implementation}

This research aimed to identify interfering aspects in the implementation of strategic human resource management in Brazilian Federal Legislative bodies, as well as the possible relations between them. Through interviews and focus groups with 16 managers of the Federal Senate and the Chamber of Deputies, 21 interfering aspects were identified, divided into institutional, political, organizational, and sectoral categories. The study elaborated theoretical-empirical models of the influences exerted by each of the aspects on the others, which supported the conclusion that the most significant constraints are of political nature, since they would define the resources and the autonomy available to human resource management units to lead the implementation process.

Keywords: strategic human resource management; human resource management in public administration; human resource management in the Legislative Power. 


\section{INTRODUÇÃO}

Com o objetivo de atender às demandas crescentes de prestação de contas e de eficiência no gasto de recursos, durante a última metade do século XX, mais notadamente nos anos 1980 e 1990, diversos governos de diferentes países iniciaram reformas, em maior ou menor grau, em um movimento denominado New Public Management (Hall \& Holt, 2008; Hammerschmid \& Walle, 2011; Hood, 1991; Peci, Pieranti, \& Rodrigues, 2008).

Iniciado no Reino Unido e disseminado para outras nações europeias e países como Estados Unidos da América (EUA), Austrália e Nova Zelândia, tal movimento pode ser visto como a preocupação crescente do setor público em adquirir características normalmente associadas aos setores produtivos da economia (Hall \& Holt, 2008; Hammerschmid \& Walle, 2011; Motta, 2013).

Em decorrência de tais reformas, Truss (2008) aponta que a gestão de pessoas (GP) no setor público recebeu atenção renovada, uma vez que novas abordagens na área poderiam facilitar o recrutamento e seleção de equipes qualificadas, aprimorar a efetividade dos custos organizacionais e servir como propulsoras de uma cultura dirigida ao desempenho.

Assim, as práticas de GP derivadas da iniciativa privada foram estabelecidas como modelos, entre as quais se pode destacar: recompensas baseadas em desempenho; redução de custos do emprego; descentralização estratégica para as unidades de recursos humanos; maior flexibilidade; e aumento da individualização das relações de trabalho (Truss, 2008).

Dessa forma, houve esforços no setor público direcionados a tentativas de adoção de uma gestão estratégica de pessoas (GEP), entendida como aquela que se alia aos tomadores de decisão e integra os objetivos de longo prazo das organizações com as necessidades relacionadas às pessoas (Lacombe \& Tonelli, 2001; Marler \& Fisher, 2013; Truss, 2008).

No Brasil, um dos reflexos das reformas introduzidas durante a década de 1990 é a tentativa de condução de práticas de GP, nos órgãos do Poder Executivo Federal, com ênfase para desempenho, resultados e excelência na prestação de serviços, por meio do estabelecimento de mecanismos para a motivação e a capacitação dos servidores públicos, como foi o caso da Política Nacional de Desenvolvimento de Pessoal (PNDP), calcada no modelo de gestão por competências (GPC), uma das possíveis vertentes estratégicas de GP (Camões, Fonseca, \& Porto, 2014).

Com poucos resultados positivos pós-implantação, a PNDP foi objeto de estudo de duas pesquisas brasileiras recentes: uma analisou a influência da autonomia das unidades de GP da Administração Pública Federal na realização bem-sucedida de atividades de treinamento e desenvolvimento, identificando contingências à consecução destas (Fonseca, 2013); outra descreveu os principais fatores interferentes no processo de implantação dessa política (Camões, 2013; Camões \& Meneses, 2016).

Em suma, os fatores e as contingências identificados demonstram a dificuldade prática de transpor um modelo originário da iniciativa privada para o setor público, ainda que adotando como critério somente uma das vertentes possíveis da GPC (capacitação) e em um único lócus e uma única esfera da Administração Pública, qual seja, o Poder Executivo Federal (Fonseca, Meneses, Silva, \& Campos, 2013).

Internacionalmente, há estudos sobre a aplicação da GEP e da GPC no contexto do setor público, podendo-se citar como um dos primeiros estudos do gênero aquele desenvolvido por Mesch, Perry e Wise (1995) no governo federal estadunidense, que identificou como fatores determinantes para a implantação bem-sucedida da GEP: graus de descentralização, de variabilidade das políticas de GP 
e de participação dos gerentes de linha, além do foco dado às políticas e práticas de GP (processos $\mathrm{x}$ resultados).

Outros estudos teórico-empíricos, conduzidos, por exemplo, na Bélgica, no Canadá, no Reino Unido e nos EUA, identificaram fatores interferentes como influência política (Brans \& Hondeghem, 2005), apoio da gerência (Bonder, Bouchard, \& Bellemare, 2011), influência de atores-chave (Truss, 2008) e habilidades do Diretor de GP (Jacobson, Sowa, \& Lambright, 2014), respectivamente.

Como todas essas pesquisas focavam o Poder Executivo, ainda há que se avaliar se tais fatores e dificuldades também estariam presentes em outros Poderes da Administração Pública, a exemplo do Legislativo brasileiro, que não está condicionado à adoção da PNDP e no qual, segundo Lamari (2010), não houve preocupação prevalente com inovação e gestão pública.

Supostamente, as reformas gerenciais e administrativas não exerceram efeitos notáveis na GP do Legislativo, cuja permeabilidade em relação a aspectos políticos parece ter favorecido a prevalência de práticas patrimonialistas de gestão sobre outras de natureza mais estratégica, estas empreendidas não como parte de um plano institucional, mas como iniciativas dos próprios gestores (Cinnanti, 2011; Guimarães, Schwartz, Souza, Melo, \& Teixeira, 2012; Guimarães, Schwartz, Werneck, \& Melo, 2015).

Focados primordialmente no funcionamento e no processo legislativos, os estudos direcionados a esse lócus ainda têm dimensões inexploradas, além de ser relativamente recentes, por remontarem em sua quase totalidade aos últimos 20 anos. No Brasil, a maioria desses estudos aborda a iniciativa legal formal e a análise das consequências da prevalência da agenda legislativa do Executivo, sendo que investigações acerca de aspectos relativos à cultura organizacional e às peculiaridades das casas legislativas são escassas (Araújo \& Silva, 2012; Inácio \& Rennó, 2009).

Assim, tal quadro, conjugado com a relativa escassez de pesquisas sobre a GEP no setor público brasileiro, aponta a necessidade de investigações acerca da implementação, no contexto da Câmara dos Deputados (CD) e do Senado Federal (SF), dos princípios da GEP (Armond, Côrtes, Santos, Demo, \& Meneses, 2016).

Portanto, esta pesquisa buscou contribuir teoricamente para o campo da Administração Pública preenchendo uma lacuna relativa à GP na esfera do Legislativo, ambiente que apresenta particularidades em sua configuração interna, além de dar continuidade a uma linha de investigações acadêmicas acerca da GEP no setor público, cujas peculiaridades, tensões e ambiguidades adicionam, aparentemente, uma camada de complexidade na etapa de implementação (Brown, 2004; Truss, 2008).

Para tal, este estudo teve por objetivo identificar aspectos interferentes na adoção dos princípios da GEP no Legislativo Federal brasileiro e, adicionalmente, estabelecer modelos hipotético-dedutivos de possíveis relações entre esses aspectos, que possam orientar investigações futuras sobre temática semelhante e iniciativas dos gestores de pessoas nessa realidade, bem como, com os devidos ajustes, em organizações dos demais poderes.

\section{GESTÃO ESTRATÉGICA DE PESSOAS}

Apesar do debate acerca do significado da GEP, é possível destacar um ponto em comum entre as propostas de estudiosos afiliados a matrizes disciplinares diversas: a compreensão de que as atividades de GP devem ser integradas entre si e com um contexto maior (Jackson, Schuler, \& Jiang, 2014).

Esse conceito de integração, elemento distintivo da GEP, teria quatro componentes: alinhamento com a estratégia de gestão e com o processo de planejamento estratégico; a coerência entre as 
políticas de GP e destas com outras políticas organizacionais; o alinhamento das atitudes e dos comportamentos dos gerentes de linha em relação à GP; e o alinhamento da força de trabalho com o negócio organizacional (Guest, 1987).

Na prática, a estruturação desses quatro componentes deveria assentar-se na análise de uma série de aspectos, entre eles a composição do estoque de recursos do capital humano (habilidades e capacidades), a especificação dos comportamentos requeridos da força de trabalho e a efetividade, em termos de resultados, das decisões diante das estratégias organizacionais, além dos fatores institucionais e políticos que influenciam a GP (Wright \& McMahan, 1992).

Em suma, tem-se que a GEP é o repensar das políticas, subsistemas, práticas e atividades de GP, de modo a assumir uma integração estratégica com os objetivos organizacionais (alinhamento vertical) e uma coesão interna à função de GP (alinhamento horizontal), considerando-se as variáveis ambientais e os múltiplos atores envolvidos, com o objetivo de facilitar a implantação dos planos da organização e alavancar seus resultados e sua capacidade de resiliência (Cascio, 2015; Lacombe \& Tonelli, 2001; Leite \& Albuquerque, 2011; C. A. Lengnick-Hall, Beck, \& M. L. Lengnick-Hall, 2011).

Historicamente, conforme revisão da literatura produzida do início dos 1980 até meados dos anos 2000 por M. L. Lengnick-Hall, C. A. Lengnick-Hall, Andrade e Drake (2009), o campo de pesquisas da GEP passou por diversos estágios de evolução, que foram organizados pelos autores de acordo com 7 grandes temas, detalhados no Quadro 1.

\section{QUADRO 1 SETE PRINCIPAIS TEMAS HISTÓRICOS DE PESQUISAS NO CAMPO DA GEP}

\begin{tabular}{|c|c|}
\hline Temática & Ideia central \\
\hline $\begin{array}{l}\text { Explicação das perspectivas de } \\
\text { contingência e ajuste }\end{array}$ & $\begin{array}{l}\text { Conjuntos particulares de práticas de GP tendem a ter melhor desempenho se } \\
\text { combinados com objetivos, condições e interesses estratégicos específicos. }\end{array}$ \\
\hline $\begin{array}{l}\text { Mudança de foco da administração } \\
\text { de recursos humanos para a criação } \\
\text { de contribuições estratégicas }\end{array}$ & $\begin{array}{l}\text { Transição da visão de administração de recursos humanos tradicional para aquela } \\
\text { baseada nas contribuições do capital humano, capacidades estratégicas e desempenho } \\
\text { organizacional competitivo, além da mudança de papel do profissional de GP. }\end{array}$ \\
\hline $\begin{array}{l}\text { Elaboração de componentes e } \\
\text { estruturas do sistema de GP }\end{array}$ & $\begin{array}{l}\text { Políticas e práticas de GP são processos complexos e interdependentes que não deveriam } \\
\text { ser considerados independentemente, mas sim examinados como subsistemas ou } \\
\text { pacotes. }\end{array}$ \\
\hline Expansão do escopo da GEP & $\begin{array}{l}\text { Mudança do foco das ações internas à organização para aquelas presentes em unidades } \\
\text { de negócio, grupos de interesse, cadeia de valor e contexto internacional. }\end{array}$ \\
\hline Implementação e execução da GEP & $\begin{array}{l}\text { Preocupação com a habilidade de uma empresa para realmente atingir as práticas de } \\
\text { GEP almejadas e os consequentes resultados estratégicos esperados. }\end{array}$ \\
\hline Mensuração dos resultados da GEP & $\begin{array}{l}\text { Determinação de medidas válidas e representativas das atividades de GEP, acerca de } \\
\text { questões como desempenho e resultados. }\end{array}$ \\
\hline $\begin{array}{l}\text { Avaliação de questões } \\
\text { metodológicas }\end{array}$ & $\begin{array}{l}\text { Importantes preocupações metodológicas decorrentes do amadurecimento do campo e } \\
\text { do estabelecimento mais completo de quadros conceituais e suposições teóricas. }\end{array}$ \\
\hline
\end{tabular}

Fonte: Adaptado de M. L. Lengnick-Hall et al. (2009). 
Uma revisão mais recente dividiu o histórico de investigações do campo de forma diferente, considerando 4 eixos principais: aspectos dos ambientes externo e interno como antecedentes do desempenho dos sistemas de GP; ligações dos sistemas de GP com resultados para atores diversos; relações mediadoras que ligam sistemas de GP a resultados para atores internos e externos; e condições ambientais que restringem ou potencializam os efeitos benéficos dos sistemas de GP (Jackson et al., 2014).

Sob um viés teórico, um trabalho seminal de Delery e Doty (1996) propôs uma categorização dos diferentes fundamentos adotados nas pesquisas sobre GEP até então em 3 possíveis perspectivas, a depender dos desenhos utilizados para entender a ligação entre a estratégia organizacional e o sistema de GP: universalista, contingencial e configuracional.

A perspectiva universalista pressupõe a existência de práticas de GP superiores, cuja adoção levaria a melhores resultados organizacionais independentemente das características das organizações e do ambiente em que atuam. Já a contingencial assume que determinadas práticas de GP são mais efetivas quando estão propriamente alinhadas às condições organizacionais, como tamanho, tempo de existência e tecnologias empregadas. Por fim, para a configuracional existiriam determinados padrões de práticas de GP mais adequadas para cada tipo de organização e sua respectiva estratégia.

Inseridas nos temas "explicação das perspectivas de contingência e ajuste" e "implementação e execução da GEP”, propostos por M. L. Lengnick-Hall et al. (2009), no último eixo delineado por Jackson et al. (2014), bem como derivadas das perspectivas teóricas contingencial e configuracional categorizadas por Delery e Doty (1996), também há as abordagens contextuais de GEP, normalmente calcadas na ideia de que os resultados obtidos são diferentes dos planejados em virtude de fatores ambientais, pois estes geram desafios ou mudanças inesperadas para a organização (Hendry \& Pettigrew, 1990; Paauwe, 2004).

As preocupações com o contexto em que a GP está inserida, tanto do ponto de vista externo quanto interno à organização, podem ser simbolizadas pelo modelo conceitual de Hendry e Pettigrew (1990), representado na Figura 1. Nele, estão presentes fatores externos, de natureza socioeconômica, técnica, político-legal e competitiva, e internos, relativos à cultura, à estrutura, à política/liderança, à tecnologia de tarefas e aos resultados organizacionais, que contribuiriam para a caracterização e o conteúdo da GP, em estreita relação com a estratégia corporativa (Hendry \& Pettigrew, 1990).

Ainda que genérico, esse modelo, ao demonstrar que o ajuste entre a estratégia organizacional e as políticas de GP é complexo e influenciado por diversos fatores dos contextos externo e interno às organizações, mostra-se útil à proposição e à testagem de modelos teóricos específicos e ajustados à realidade da Administração Pública brasileira, ainda mais se considerado que esse setor, tendente à importação de princípios e preceitos consolidados no setor privado, enfoca resultados de interesse público e não privados, ou particulares, o que pode tornar mais difícil a transformação da unidade de GP em uma parceira estratégica (Brown, 2004; Camões \& Meneses, 2016; Fonseca et al., 2013; Paauwe, 2004; Truss, 2008).

Delineado o enquadramento teórico da pesquisa, compulsou-se a literatura em busca de relatos científicos que indicassem possíveis aspectos contextuais com impacto para a implementação da GEP no setor público, com o intuito de compor um quadro de referência para a elaboração do instrumento de coleta de dados e posterior análise destes, conforme etapas descritas na seção de procedimentos metodológicos. A síntese dos aspectos identificados e do enquadramento destes em categorias consta do Quadro 2. 


\section{FIGURA 1 MODELO CONTEXTUAL DE GP}

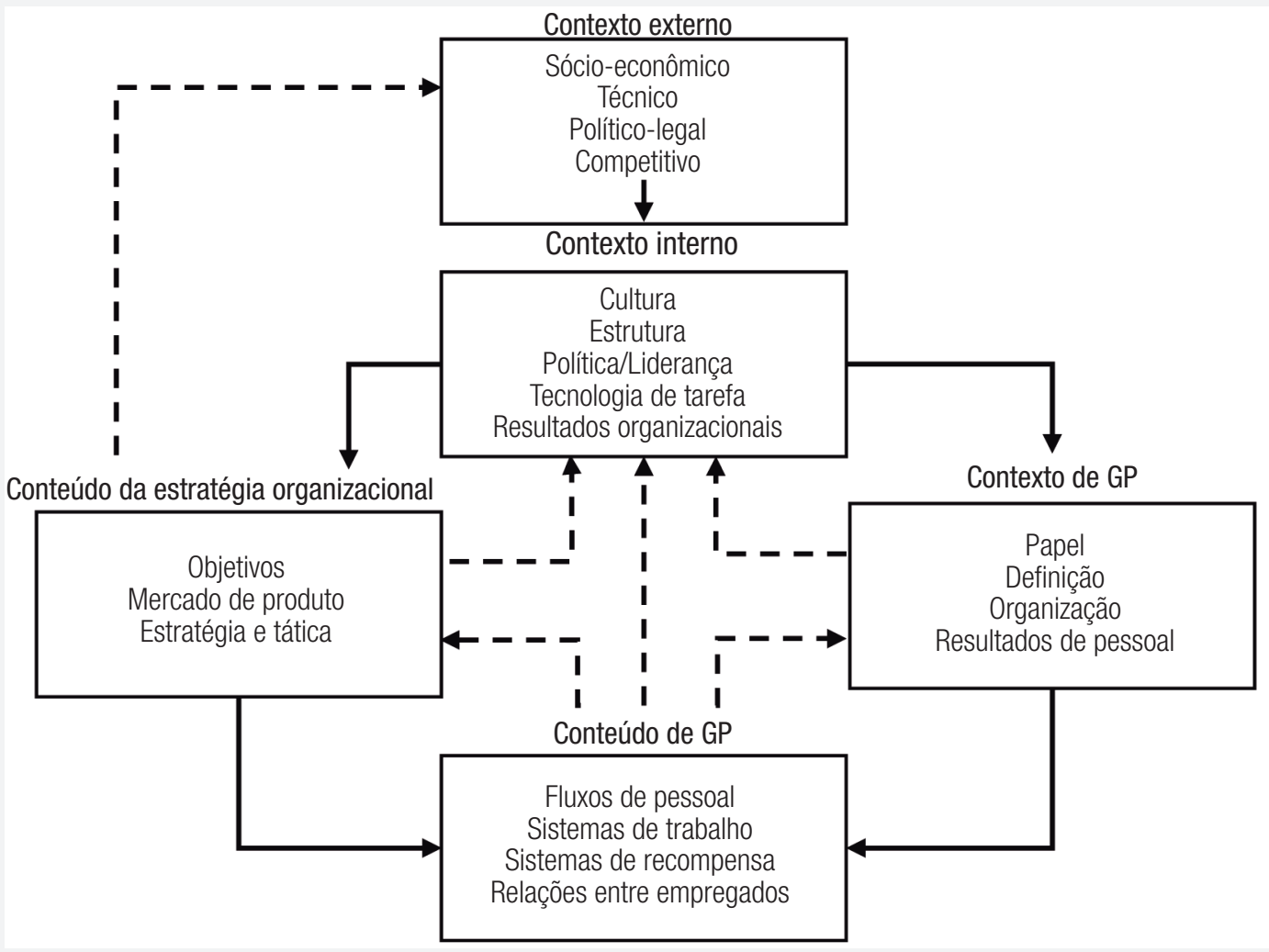

Fonte: Adaptada de Hendry e Pettigrew (1990).

\section{QUADRO 2 CATEGORIAS E ASPECTOS INTERFERENTES NA GEP DO PODER LEGISLATIVO FEDERAL BRASILEIRO}

\begin{tabular}{|c|c|c|}
\hline Categorias & Aspectos & Referências \\
\hline \multirow{3}{*}{ Institucional } & Características societais & $\begin{array}{l}\text { Fonseca e Meneses (2016); Fonseca (2013); Fonseca et al. (2013); } \\
\text { Lodge e Hood (2003); Ring e Perry (1985); Truss (2008). }\end{array}$ \\
\hline & Legislação e normas externas & $\begin{array}{l}\text { Camões (2013); Camões e Meneses (2016); Camões et al. (2014); } \\
\text { Fonseca e Meneses (2016); Fonseca et al. (2013); Šiugždinienė } \\
\text { (2006); M. A. M. Lima e I. V. Lima (2013); Mello e Amâncio (2010); } \\
\text { Randma-Liiv e Järvalt (2011); Ring e Perry (1985); Silva e Mello } \\
\text { (2013); R. L. S. Souza (2004); Teixeira, Bassotti e Santos (2013). }\end{array}$ \\
\hline & Mecanismos de controle externo & $\begin{array}{l}\text { Järvalt e Randma-Liiv (2010); Ring e Perry (1985); Teixeira et al. } \\
\text { (2013). }\end{array}$ \\
\hline
\end{tabular}




\begin{tabular}{|c|c|c|}
\hline Categorias & Aspectos & Referências \\
\hline \multirow{5}{*}{ Política } & Configuração política da organização & $\begin{array}{l}\text { Anselmi, Lazzini e Zarone (2013); Bergue (2014); Camões (2013); } \\
\text { Camões e Meneses (2016); Fonseca et al. (2013); Harris (2005); } \\
\text { Hondeghem, Horton e Scheepers (2006); Ingraham e Rubaii- } \\
\text { Barrett (2007); Järvalt e Randma-Liiv (2010); Ring e Perry (1985); } \\
\text { Šiugždinienė (2006); Teixeira et al. (2013); Truss (2008). }\end{array}$ \\
\hline & Apoio da alta administração & $\begin{array}{l}\text { Bergue (2014); Camões et al. (2014); Fonseca e Meneses (2016); } \\
\text { Fonseca (2013); Järvalt e Randma-Liiv (2010); Lem (2011); } \\
\text { Randma-Liiv e Järvalt (2011); Šiugždinienė (2006); Terabe e } \\
\text { Bergue (2014); Truss (2008). }\end{array}$ \\
\hline & Descontinuidade administrativa & $\begin{array}{l}\text { Camões (2013); Camões e Meneses (2016); Fonseca e Meneses } \\
\text { (2016); Fonseca (2013); Järvalt e Randma-Liiv (2010); Ring e } \\
\text { Perry (1985); Teixeira et al. (2013). }\end{array}$ \\
\hline & Habilidade política da liderança de GP & $\begin{array}{l}\text { Brans e Hondeghem (2005); Camões (2013); Camões e Meneses } \\
\text { (2016); Fonseca (2013); Fonseca et al. (2013); Ingraham e Rubaii- } \\
\text { Barret (2007); Jacobson et al. (2014). }\end{array}$ \\
\hline & Inserção estratégica da unidade de GP & Fonseca (2013); Ingraham e Rubaii-Barret (2007); Teo (2002). \\
\hline \multirow{6}{*}{ Organizacional } & Características culturais & $\begin{array}{l}\text { Fonseca e Meneses (2016); M. A. M. Lima e I. V. Lima (2013); Mello e } \\
\text { Amâncio (2010); Silva e Mello (2013); Ubeda e Santos (2008). }\end{array}$ \\
\hline & Recursos organizacionais & Camões (2013); Camões e Meneses (2016); Vo e Bartram (2012). \\
\hline & Estrutura organizacional & $\begin{array}{l}\text { Camões (2013); Camões e Meneses (2016); Daley e Vasu } \\
\text { (2005); Fonseca (2013); Fonseca e Meneses (2016); Fonseca } \\
\text { et al. (2013); Harris (2005); Ingraham e Rubaii-Barrett (2007); } \\
\text { Järvalt e Randma-Liiv (2010); Lodge e Hood (2003); Ring e Perry } \\
\text { (1985); Silva e Mello (2013); R. L. S. Souza (2004); Teixeira et al. } \\
\text { (2013); Truss (2008); Ubeda e Santos (2008); Vo e } \\
\text { Bartram (2012). }\end{array}$ \\
\hline & Engajamento de gestores e servidores & $\begin{array}{l}\text { Bergue (2014); Bonder et al. (2011); Camões (2013); Camões } \\
\text { e Meneses (2016); Farnham e Stevens (2000); Fonseca (2013); } \\
\text { Hondeghem et al. (2006); Mesch et al. (1995); Silva e Mello (2013); } \\
\text { Teo (2002); Terabe e Bergue (2014); Ubeda e Santos (2008). }\end{array}$ \\
\hline & Comunicação institucional & $\begin{array}{l}\text { Farnham e Stevens (2000); Harris (2005); Lodge e Hood (2003); } \\
\text { Pichault (2007); Ring e Perry (1985); Silva e Mello (2013). }\end{array}$ \\
\hline & Normas internas & Guimarães et al. (2012). \\
\hline
\end{tabular}




\begin{tabular}{|c|c|c|}
\hline Categorias & Aspectos & Referências \\
\hline \multirow{7}{*}{ Setorial } & Integração estratégica de GP & $\begin{array}{l}\text { Camões (2013); Camões e Meneses (2016); Fonseca e Meneses } \\
\text { (2016); Järvalt e Randma-Liiv (2010); Lem (2011); M. A. M. Lima } \\
\text { e I. V. Lima (2013); Mello e Amâncio (2010); Mesch et al. (1995); } \\
\text { Pichault (2007); Ring e Perry (1985); Teixeira et al. (2013); Ubeda } \\
\text { e Santos (2008). }\end{array}$ \\
\hline & Reputação da unidade de GP & $\begin{array}{l}\text { Fonseca (2013); Fonseca et al. (2013); Ingraham e Rubaii-Barrett } \\
\text { (2007); Jacobson et al. (2014); Ring e Perry (1985); Teo (2002). }\end{array}$ \\
\hline & Recursos da unidade de GP & $\begin{array}{l}\text { Bergue (2014); Camões (2013); Camões e Meneses (2016); } \\
\text { Farnham e Stevens (2000); Fonseca (2013); Fonseca e Meneses } \\
\text { (2016); Mello e Amâncio (2010); Šiugždinienè (2006); R. L. S. Souza } \\
\text { (2004); Terabe e Bergue (2014); Vo e Bartram (2012). }\end{array}$ \\
\hline & Autonomia da unidade de GP & $\begin{array}{l}\text { Camões (2013); Camões e Meneses (2016); Fonseca et al. } \\
\text { (2013); Järvalt e Randma-Liiv (2010); Mesch et al. (1995); Teixeira } \\
\text { et al. (2013); Vo e Bartram (2012). }\end{array}$ \\
\hline & Estrutura da unidade de GP & Ubeda e Santos (2008). \\
\hline & Metodologia de implementação & $\begin{array}{l}\text { Boyett e Currie (2001); Camões (2013); Camões e Meneses } \\
\text { (2016); Fonseca et al. (2013); Fonseca e Meneses (2016); } \\
\text { Hondeghem et al. (2006); Lem (2011); Pichault (2007); Ring e } \\
\text { Perry (1985); Šiugždinienė (2006); Truss (2008). }\end{array}$ \\
\hline & Coexistência do papel funcional de GP & $\begin{array}{l}\text { Fonseca et al. (2013); Mello e Amâncio (2010); Mesch et al. } \\
\text { (1995); Teo (2002); Vo e Bartram (2012). }\end{array}$ \\
\hline
\end{tabular}

Fonte: Elaborado pelos autores.

Portanto, a categoria de interferentes institucionais abarca elementos do ambiente externo das organizações públicas que influenciam seu funcionamento, sua estruturação e a orientação de suas atividades e, obviamente, as políticas e práticas de GP (Fonseca, 2013). Já os políticos derivam da dinâmica e dos relacionamentos intra e, principalmente, intergrupais, sendo associados à formação de agenda e à tomada de decisões a partir de questões como poder, uso de influência, conflito de interesses, construção de coalizões, negociação e barganha (Camões \& Meneses, 2016).

Os interferentes da categoria organizacional, por sua vez, compõem o ambiente interno das organizações públicas, revelando-se em sua organização interna, estrutura hierárquica, cultura organizacional, relações interpessoais e processos. Por fim, os setoriais se referem a elementos sob controle direto da unidade de GP e aspectos que a definem ou que decorrem do estilo de atuação e dos atributos e habilidades do seu dirigente e de sua equipe de servidores (Fonseca, 2013).

Para cumprir com os objetivos desta pesquisa, isto é, verificar quais facilitadores e restrições estão presentes nos órgãos do Poder Legislativo Federal brasileiro, os princípios da GEP relacionados aos alinhamentos vertical e horizontal, as categorias antes apontadas (institucional, organizacional, política e setorial) e os atores (grupos de interesse e alta administração) que influenciam as políticas e práticas de GP foram inseridos em uma adaptação da proposição de Hendry e Pettigrew (1990), culminando na elaboração de um modelo (Figura 2) que orientou esta investigação. 
FIGURA 2 MODELO CONTEXTUAL DE INVESTIGAÇÃO SOBRE A IMPLEMENTAÇÃO DA GEP NO LEGISLATIVO FEDERAL BRASILEIRO

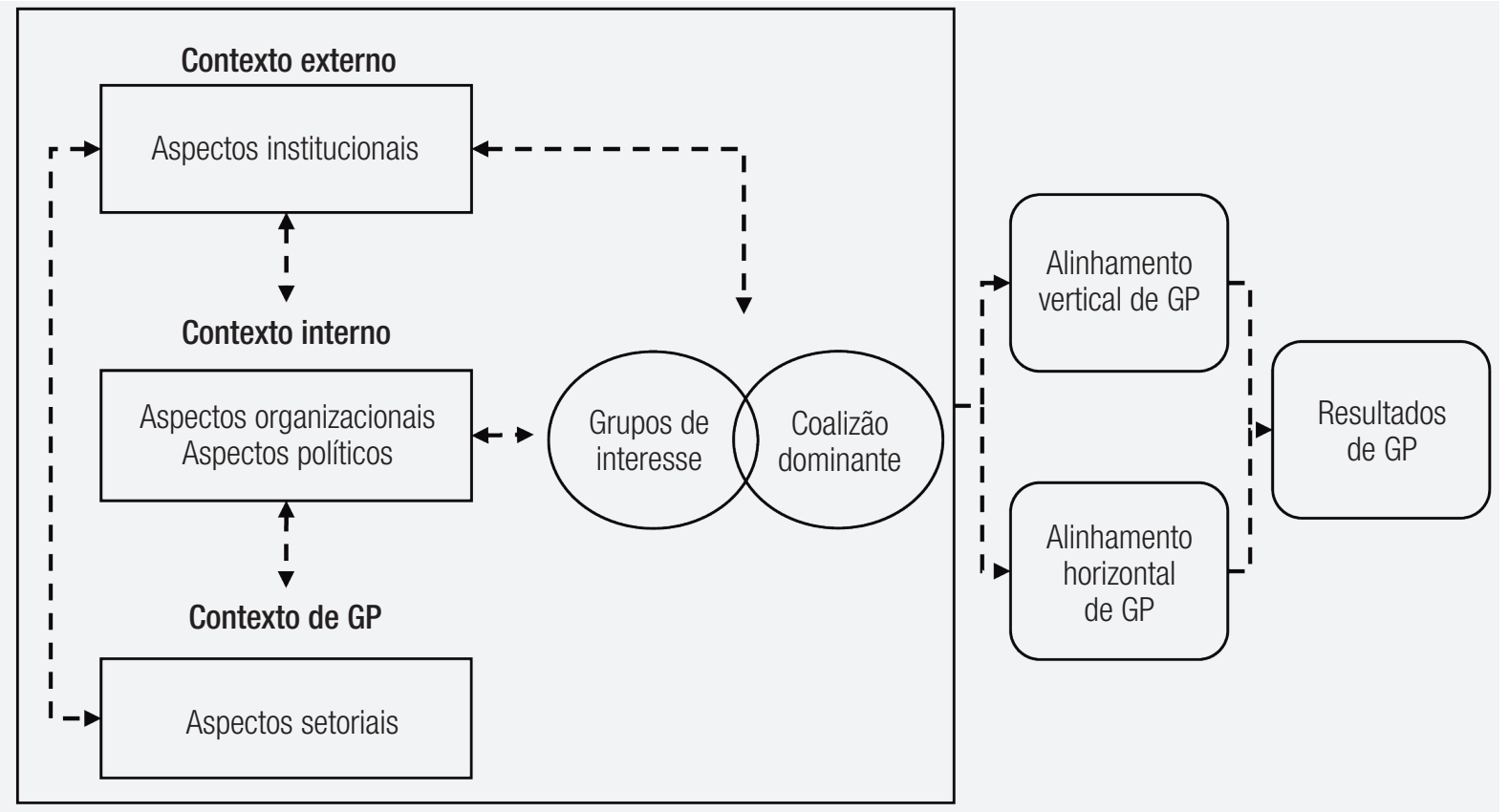

Fonte: Elaborada pelos autores.

Os aspectos da categoria institucional foram enquadrados como pertencentes ao contexto externo do modelo de Hendry e Pettigrew (1990); os da organizacional e política, ao contexto interno do mesmo modelo; e os da setorial, próprios da unidade de GP foram considerados parte do contexto de GP definido pelos autores.

Os 3 tipos de contexto e os 4 tipos de interferentes aparentemente afetariam uns aos outros, em um complexo sistema de interações (Fonseca et al., 2013; Hendry \& Pettigrew, 1990; Paauwe, 2004), que também envolveria atores organizacionais, como a alta administração (Bergue, 2014), grupos de interesse em geral (Järvalt \& Randma-Liiv, 2010; Truss, 2008; Tsui, 1987), gerentes de linha (Guest, 1987; Mesch et al., 1995; Teo, 2002) e servidores (Camões \& Meneses, 2016; Vo \& Bartram, 2012).

O resultado dessas interações e da ação dos diversos atores interferiria na integração estratégica da área, relativamente aos seus níveis de alinhamento horizontal e vertical (Camões \& Meneses, 2016; Fonseca, 2013; Guest, 1987; Paauwe, 2004; Wright \& McMahan, 1992), o que, por sua vez, seria um dos determinantes dos resultados das políticas e práticas de GP (Guest, 1987; Paauwe, 2004).

As escolhas metodológicas, a elaboração dos instrumentos e a análise de dados deste estudo foram fundamentadas nesse modelo, sobretudo na categorização de interferentes predefinida, de modo a permitir a verificação de que condicionantes estão presentes no Legislativo Federal brasileiro, como se relacionam entre eles e como essas interações afetam os alinhamentos vertical e horizontal da GP e, consequentemente, seus resultados. 


\section{PROCEDIMENTOS METODOLÓGICOS}

A pesquisa consistiu de um levantamento de opiniões, em que o pesquisador busca informações de pessoas experientes em alguma área de estudo, por meio da coleta de dados de suas memórias, experiências e ideias sobre determinado campo do conhecimento, uma vez que o objetivo específico envolvia a verificação, com base na vivência dos indivíduos que trabalham no Poder Legislativo, da existência de fatores interferentes na implementação dos princípios da GEP (Cooper \& Schindler, 2014).

A natureza da pesquisa foi descritiva, com abordagem qualitativa (Cooper \& Schindler, 2014; Creswell, 2014). O universo da pesquisa compreendeu as duas casas legislativas federais brasileiras, CD e SF, e a seleção dos participantes foi realizada via amostragem rígida (Flick, 2007), já que todos foram convidados devido à posição gerencial que ocupavam dentro da unidade de GP, sendo que os indivíduos de um órgão tinham funções similares ou equivalentes aos do outro órgão, de modo a obter relatos daqueles que mais vivenciavam a proximidade com o planejamento organizacional e de GP e, portanto, tinham mais condições de conhecer possíveis aspectos interferentes na implementação de princípios da GEP.

Com o objetivo de captar a significação dada ao fenômeno pelos diferentes participantes e de aprimorar os resultados, adotou-se a triangulação na coleta de dados, por meio da utilização de dois instrumentos diferentes (Tran, 2015): um roteiro de entrevista semiestruturado e um roteiro de grupo focal (Flick, 2007).

Para a construção do primeiro instrumento, utilizaram-se subsídios constantes de relatos científicos, identificados por meio de busca exploratória, acerca de prováveis interferências do contexto na adoção da GEP na Administração Pública. A partir da leitura desse material, os trechos que apontavam possíveis interferentes à aplicação da GEP no setor público foram extraídos e organizados em uma planilha, com posterior identificação de aspectos contextuais por artigo, homogeneização dos nomes dos aspectos e agrupamento destes, por similaridade, em quatro categorias: institucionais; políticos; organizacionais; e setoriais (Quadro 2).

Tais categorias foram definidas a partir da proposta de pesquisadores nacionais que têm se dedicado à aplicação do tema, sobremaneira, no Poder Executivo Federal (p. ex., Camões \& Meneses, 2016; Fonseca, 2013), também observando as regras de categorização de Bardin (2011): exclusão mútua; homogeneidade; pertinência; objetividade; e produtividade.

Portanto, o primeiro roteiro foi elaborado a partir da literatura sobre princípios de GEP e dos referidos tipos de contingências envolvidas em sua implementação no setor público, em conformidade com o modelo apresentado na Figura 2. Foram feitas perguntas relativas aos seguintes tópicos: objetivos da GP nas organizações; planejamento das políticas e práticas de GP; contribuição da GP para a consecução dos objetivos organizacionais; grau de alinhamento entre subsistemas de GP; variáveis ambientais; e grupos de interesse com interferência positiva ou negativa para a condução das atividades de GP.

Já o roteiro de grupo focal foi elaborado a partir de uma situação hipotética de implementação da GEP nas organizações estudadas, para que os participantes fossem instigados a trocar opiniões sobre quais dificuldades enfrentariam, quais facilidades encontrariam e como conduziriam o processo de mudança caso compusessem a equipe responsável pela transição, tudo com base em suas experiências e conhecimentos passados e nas categorias de aspectos interferentes que constam no Quadro 2. 
Após uma aplicação piloto a 2 indivíduos, para verificar a adequação do instrumento, as entrevistas abrangeram, ao todo, 8 indivíduos, todos servidores efetivos, sendo 4 gestores da unidade de GP de cada casa, enquanto os 2 grupos focais foram realizados com outros 4 gestores de GP de cada, culminando em uma amostra de 16 participantes, cujos dados demográficos básicos são sintetizados na Tabela 1.

\section{TABELA 1 DADOS DEMOGRÁFICOS BÁSICOS DOS PARTICIPANTES}

\begin{tabular}{ccccc} 
Código & Sexo & Tempo na organização (em anos) & Tempo na função gerencial (em anos) \\
\hline Participante 1 & Masculino & 24 & 15 \\
Participante 2 & Masculino & 6 & 0,2 \\
Participante 3 & Feminino & 32 & 1 \\
Participante 4 & Feminino & 20 & 3 \\
Participante 5 & Masculino & 17 & 12 \\
Participante 6 & Masculino & 31 & 4 \\
Participante 7 & Masculino & 27 & 2 \\
Participante 8 & Masculino & 6 & 1,5 \\
Participante 9 & Masculino & 34 & 13 \\
Participante 10 & Feminino & 24 & 18 \\
Participante 11 & Masculino & 25 & 13 \\
Participante 12 & Masculino & 14 & 9 \\
Participante 13 & Masculino & 33 & 2 \\
Participante 14 & Masculino & 7 & 0,5 \\
Participante 15 & Feminino & 20 & 4 \\
Participante 16 & Masculino & 4 & 1,5 \\
\hline
\end{tabular}

Fonte: Elaborada pelos autores.

Todos os dados coletados foram tratados conjunta e integradamente, tanto em termos de órgão de origem quanto de instrumento utilizado na coleta, por meio de análise de conteúdo pré-categórica, uma vez que as categorias e respectivos aspectos haviam sido previamente identificados durante a revisão de literatura (Bardin, 2011).

Por fim, após concluída a análise de conteúdo, os trechos relativos aos aspectos identificados foram reavaliados para verificar a menção de relações entre eles, o que possibilitou a elaboração de modelos teórico-empíricos para entendimento da GEP no Legislativo Federal brasileiro, bem como hipotético-dedutivos para futuras investigações acerca de GEP no setor público. 


\section{RESULTADOS E DISCUSSÃO}

Como proposto, este estudo concentrou-se inicialmente em identificar as interferências possíveis na implementação dos princípios da GEP no Poder Legislativo Federal brasileiro. A partir das evidências reunidas, foram identificados 21 aspectos interferentes, enquadrados nos 4 tipos de categorias mencionadas na seção de referencial teórico (institucional, política, organizacional e setorial), como demonstrado na Tabela 2, que também apresenta a recorrência total de cada aspecto nas falas dos participantes das entrevistas e dos grupos focais.

\section{TABELA 2 CATEGORIAS E ASPECTOS INTERFERENTES NA GEP DO PODER LEGISLATIVO FEDERAL} BRASILEIRO

\begin{tabular}{|c|c|c|}
\hline Categorias & Aspectos & Recorrência total \\
\hline \multirow{3}{*}{ Institucional } & Características societais & 28 \\
\hline & Legislação e normas externas & 23 \\
\hline & Mecanismos de controle externo & 17 \\
\hline \multirow{5}{*}{ Política } & Configuração política da organização & 58 \\
\hline & Apoio da alta administração & 27 \\
\hline & Descontinuidade administrativa & 21 \\
\hline & Habilidade política da liderança de GP & 13 \\
\hline & Inserção estratégica da unidade de GP & 11 \\
\hline \multirow{6}{*}{ Organizacional } & Características culturais & 42 \\
\hline & Recursos organizacionais & 29 \\
\hline & Estrutura organizacional & 20 \\
\hline & Engajamento de gestores e servidores & 20 \\
\hline & Comunicação institucional & 14 \\
\hline & Normas internas & 8 \\
\hline \multirow{7}{*}{ Setorial } & Integração estratégica de GP & 23 \\
\hline & Reputação da unidade de GP & 20 \\
\hline & Recursos da unidade de GP & 19 \\
\hline & Autonomia da unidade de GP & 12 \\
\hline & Estrutura da unidade de GP & 11 \\
\hline & Metodologia de implementação & 10 \\
\hline & Coexistência do papel funcional de GP & 10 \\
\hline
\end{tabular}

Fonte: Elaborada pelos autores. 
Os aspectos identificados são explanados a partir da perspectiva dos participantes, com exemplos de suas falas, e, quando necessário, discutidos com a utilização da literatura existente sobre o tema, bem como são apontadas as possíveis interferências que exercem sobre outros aspectos. Esgotado o detalhamento dos resultados relativos aos aspectos de cada categoria, apresenta-se um modelo teórico-empírico e hipotético-dedutivo das interferências mencionadas no decorrer do texto.

Assim, dentre os aspectos pertencentes à categoria institucional, a mais citada pelos participantes das entrevistas e grupos focais tratou das características societais, concernentes à conjuntura econômica, macropolítica e social externa que deve ser considerada no caso da implementação dos princípios da GEP no Legislativo Federal. Considerando o cenário brasileiro atual, tais características acabam por desviar o foco da alta liderança dos assuntos de GP para temas mais urgentes, o que exige uma atuação permanente da unidade de GP para a conquista do apoio desse grupo de atores (1), o que é ainda mais difícil em razão da marcante descontinuidade administrativa existente nessa esfera de poder. Esta, por sua vez, também é mais acentuada devido ao próprio cenário político nacional e às consequentes e recorrentes composições partidárias com ocupação de cargos do Executivo por Senadores e Deputados Federais (2).

Um ator externo que certamente nos afeta muito na gestão de pessoas é a mídia, os jornalistas, a mídia, porque nós temos aquele fish ball effect, de você tá se sentindo num aquário um peixe sempre vigiado, num aquário transparente, e qualquer coisa que você tente qualificar na gestão de pessoas pode ser bem interpretado pelos servidores e pode ser mal visto pela sociedade, por uma desvirtuação daquele fato administrativo por parte da mídia [...] então, qualquer benefício adicional que se pense em dar há sempre uma possibilidade ou às vezes acontece de fato de que uma determinada atitude que seria muito favorável, positiva, pros servidores, em termos até de atender os próprios compromissos de qualidade de vida das pessoas, ele possa ser mal interpretado pela mídia, disseminado pela mídia [...] se nós pegarmos os três poderes, o poder mais criticado é sempre o Poder Legislativo (Participante 2).

Também remeteram em suas falas, os participantes, a questões relativas à legislação e normas externas, cujas mudanças constantes, excesso e fragmentação geram uma carga adicional de trabalho para as unidades de GP. Ainda que algumas inovações legais possam ajudar essas unidades a mitigar a sobreposição de critérios técnicos por políticos em suas próprias decisões (3), outras exigem esforços operacionais das unidades para que se altere rotinas e procedimentos, em detrimento da execução de atividades estratégicas (4), o que se coaduna com os resultados da pesquisa de Teo (2002) em uma organização do setor público australiano. Já o excesso e a fragmentação de leis e normas externas que regulamentam a GP tendem a gerar conflitos na interpretação e aplicação dessas regras, dificuldade de elaboração de normas internas que não sejam conflitantes com as externas (5), podendo, ainda, criar barreiras à integração e à interdependência entre os diversos subsistemas de GP (6), como também apontam Camões et al. (2014).

As normas que são implementadas também, uma medida provisória pro Executivo, que tentam restringir admissão ou tentam alterar direitos pras próximas gerações de servidores públicos também impactam aqui dentro, porque você tem que moldar as regras de transição, porque frente à instituição do direito adquirido, quando há uma alteração legal, não que você vá retroceder, mas os novos servidores vão passar a ser subordinados àquela regra nova, por exemplo, a regra previdenciária, 
da previdência complementar, então, tem que ter todo um ganho de conhecimento e de gestão sobre aquilo, aquela nova regra, pra você conseguir implementar, né, e isso é constante (Participante 8).

Um último ponto destacado pelos participantes, relativo à categoria de fatores institucionais, referiu-se aos mecanismos de controle externo, especificamente a requisições provenientes de auditorias das cortes de contas, a demandas judiciais de atendimento obrigatório e à necessidade de observação de entendimentos jurisprudenciais. Reflexos diretos do arcabouço legal e normativo brasileiro, essas demandas implicam, similarmente ao notado no aspecto anterior, a concentração de esforços dos setores de GP nas questões legal-formais de pessoal aventadas nas recomendações e cobranças dos órgãos de controle e judiciais, que tendem a reduzir a oportunidade de uma atuação inovadora e estratégica por parte desses setores (7).

[...] a Suprema corte, né, o Supremo Tribunal Federal, é, precisa às vezes imiscuir-se e tomar determinadas posições que engessam ou impossibilitam que os gestores políticos, eu digo a alta administração, tanto da Câmara quanto Senado, se vê, é, constrangida a cumprir, né, a dar cumprimento, ordem judicial não se discute (Participante 3).

De modo geral, nota-se que os aspectos da categoria institucional podem afetar aspectos pertencentes a outros tipos de categoria, em especial os políticos e os setoriais (ver Figura 3). Assim, pode-se inferir que o corpo legal-normativo externo às organizações do Poder Legislativo e os consequentes controles externo e judicial impactam mais a realidade das unidades de GP, em seu ritmo de trabalho e sua flexibilidade para inovar e promover mudanças estruturais, enquanto questões econômicas, macropolíticas, sociais e midiáticas influenciam mais a formação de agenda dos dirigentes dessas organizações e o nível de apoio que eles estão dispostos a fornecer às unidades de GP para a consecução de suas políticas e práticas.

\section{FIGURA 3 MODELO TEÓRICO-EMPÍRICO DE INTERFERÊNCIAS EXERCIDAS PELOS ASPECTOS INSTITUCIONAIS}

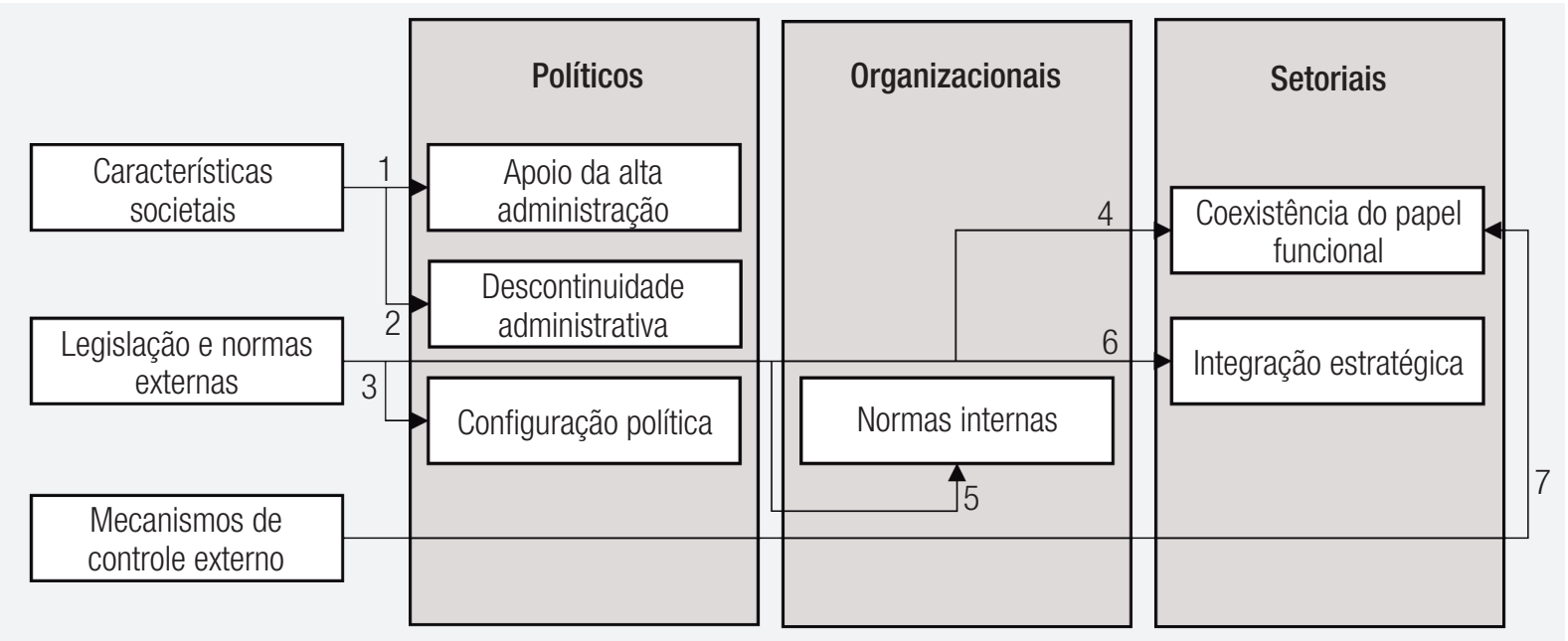

Fonte: Elaborada pelos autores. 
Em relação à categoria política, o aspecto mais citado foi a configuração política da organização, relativa ao padrão de uso das influências e de critérios políticos na formação da agenda da alta cúpula, uma vez que a própria natureza das casas legislativas geraria processos administrativos e decisórios, inclusive de GP, muito mais sujeitos a negociações e interferências de vários grupos de atores, frequentemente por meio de critérios outros que não técnicos. Isso pode acarretar em baixo apoio da alta administração às atividades da unidade de GP (1) e, consequentemente, em decisões sem vínculo com os objetivos organizacionais, comprometendo o alinhamento vertical da área (2).

[...] o RH não toma as decisões de como a gestão de recursos humanos vai ser feita na casa [...] a nossa instância maior, né, é a Mesa Diretora, por mais que tenhamos uma Diretoria-Geral, a Diretoria-Geral se reporta à Mesa Diretora, inúmeras decisões que dizem respeito à gestão de $R H$ na casa são tomadas pela Mesa, em outras palavras, são decisões políticas (Participante 5).

Tais constatações são similares ao exposto por Ingraham e Rubaii-Barrett (2007), que assumem como um dos principais problemas da GP no setor público justamente a superação das diferenças de enfoque e de visão dos agentes políticos e gestores politicamente indicados relativamente aos dirigentes de GP, o que pode prejudicar a integração das políticas e práticas de GP aos objetivos da organização.

O próximo aspecto, intrinsecamente ligado ao anterior, é o apoio da alta administração. A alta administração das casas do Congresso Nacional tem duas instâncias: uma puramente administrativa, que é a Diretoria-Geral, e outra de caráter político-administrativo, denominada Comissão ou Mesa Diretora. Os relatos demonstram que, quando tais atores não entendem a importância da GP para o cumprimento dos propósitos organizacionais, é inviável que as unidades de GP, isoladamente, tentem implementar os princípios da GEP, à semelhança do que a literatura indica, já que para mudanças nas políticas e práticas de GP seriam necessárias decisões favoráveis por parte desses dois grupos para garantir recursos ou autonomia (3), o que também auxiliaria na obtenção de maior engajamento de servidores e gestores (4), pois estes aceitariam melhor a atuação da unidade de GP (Fonseca \& Meneses, 2016).

[...] eu diria que há, via de regra, necessidade de que a alta administração, e por que não dizer a Mesa Diretora, e basicamente o Primeiro-Secretário, que tem essa interface como o administrador, é... maior na questão administrativa em relação ao servidor, é preciso que haja uma sintonia fina entre a unidade de gestão de pessoas e a Primeira-Secretaria, e a sensibilidade desse gestor, do Primeiro Secretário, com relação às demandas de RH (Participante 3).

Outro aspecto que é, de certa forma, consequência da configuração política e até do mandamento constitucional sobre a duração de dois anos dos mandatos das Comissões Diretoras de cada uma das casas legislativas é a descontinuidade administrativa. O entendimento geral é de que, a cada eleição desse colegiado, há mudanças dos titulares dos cargos de Diretor-Geral e de Diretor da unidade de GP, o que pode interromper ou modificar ciclos do planejamento estratégico organizacional até então em execução e, consequentemente, as prioridades da cúpula (5) e até um efeito cascata de abandono ou reformulações completas de projetos de GP de longo prazo, com possíveis prejuízos para o nível de integração estratégica de GP até então existente (6). 
[...] com relação à descontinuidade administrativa é o que a gente tem acompanhado aí nos últimos anos, trocas incessantes de diretores, aquela política estabelecida ela não chega nem ao seu primeiro capitulo de ação, porque no passo seguinte a direção é substituída e por aí vai, tá sempre recomeçando, né, e eu acho que recomeçar você praticamente inicia um novo procedimento, que nunca se termina (Participante 13).

Segundo Ring e Perry (1985), um dos comportamentos mais importantes na gestão de processos estratégicos, com vistas a contornar fatores e restrições contextuais, é justamente a tentativa de gerenciar e minimizar a descontinuidade e as lacunas dela decorrentes, por meio da sensibilidade ao cenário político, sendo importante para os gestores, como os de GP, terem conhecimentos técnicos e habilidades de relacionamento no trato com os grupos e atores envolvidos e de criação e manutenção de alianças, como as capacidades políticas (7), que constituem o próximo aspecto a ser abordado.

Esse aspecto, denominado habilidade política da liderança de GP, é enxergado pelos participantes sob o prisma das capacidades de influência detidas pelo dirigente da unidade de GP, utilizada por ele para o convencimento de atores por meio de processos de negociação. Tal achado corrobora resultados de pesquisas que apontam como item fundamental na implementação da GEP o papel da liderança na demonstração, para os diversos grupos de interesse e para as arenas decisórias, do caráter estratégico e da importância da GP para o desempenho organizacional (Jacobson et al., 2014).

[...] então a gestão de pessoas ela passa muito por essa capacidade que você tem de argumentação, de persuasão, de convencimento, é... porque todos os, os, os grupos são importantes aí [...] normalmente, quando você vai na Diretoria-Geral com um projeto, é... ou na Mesa Diretora, vocêfala assim "vamos investir em mestrado?", até vai, porque não é muito caro, quando você transforma isso com nomes de pessoas ali, a coisa se complica mais, então, eu diria que a parte de pessoas que influenciam na, na, na política de RH, é essa dificuldade que eu tenho de convencimento, e você tem dois... sempre que você trabalha com pessoas você tem dois grupos: você tem o grupo acima, que você tem uma dificuldade grande de convencer, e você tem que convencer os servidores da importância daqueles programas também (Participante 7).

Assim, essas habilidades de natureza política do Diretor de GP são importantes para que ele consiga atuar bem nas instâncias superiores, de modo que podem auxiliar na transição gradual de um papel funcional para o estratégico no setor público e na reversão de uma má reputação (8) (Fonseca et al., 2013; I. G. L. Souza, 2016; Truss, 2008).

Por fim, há o aspecto inserção estratégica da unidade de GP, cujas menções recaíram sobre o grau de participação da unidade de GP ou no planejamento organizacional ou nas decisões sobre políticas, práticas e projetos de GP, além de abordarem o nível de convergência da área com a alta administração. Verificou-se que tal inserção ainda é incipiente, podendo ser trabalhada para que exista maior presença de seus líderes ou representantes nas arenas e nos processos decisórios de questões atinentes à área, com maior autonomia (9), traduzida em liberdade para discussão, formulação, monitoramento e revisão de propostas e planos (Ingraham \& Rubaii-Barret, 2007; Sheehan, Cieri, Cooper, \& Brooks, 2015). 
[...] às vezes as decisões são tomadas e as normas são feitas, às vezes internamente sem nos ouvir, isso às vezes impacta, e aí cria um certo, um certo reboliço, cria um certo estremecimento, você tem que trazer todo mundo de volta (Participante 6).

Diante do exposto e como ilustrado na Figura 4, infere-se que os aspectos políticos, cujas características são em parte moldadas pelo ambiente institucional, também têm efeitos entre si, já que a configuração política da organização e a acentuada descontinuidade administrativa afetam e integram o complexo processo decisório do Poder Legislativo Federal conduzido pela alta administração, com influência no nível de engajamento de gestores e servidores e nas políticas e práticas de GP que, para ser estrategicamente integradas de forma efetiva, precisariam que toda essa conjuntura política fosse favorável, o que aparentemente poderia ser facilitado pela existência de um dirigente de GP que trabalhasse a reputação da área.

\section{FIGURA 4 MODELO TEÓRICO-EMPÍRICO DE INTERFERÊNCIAS EXERCIDAS PELOS ASPECTOS POLÍTICOS}

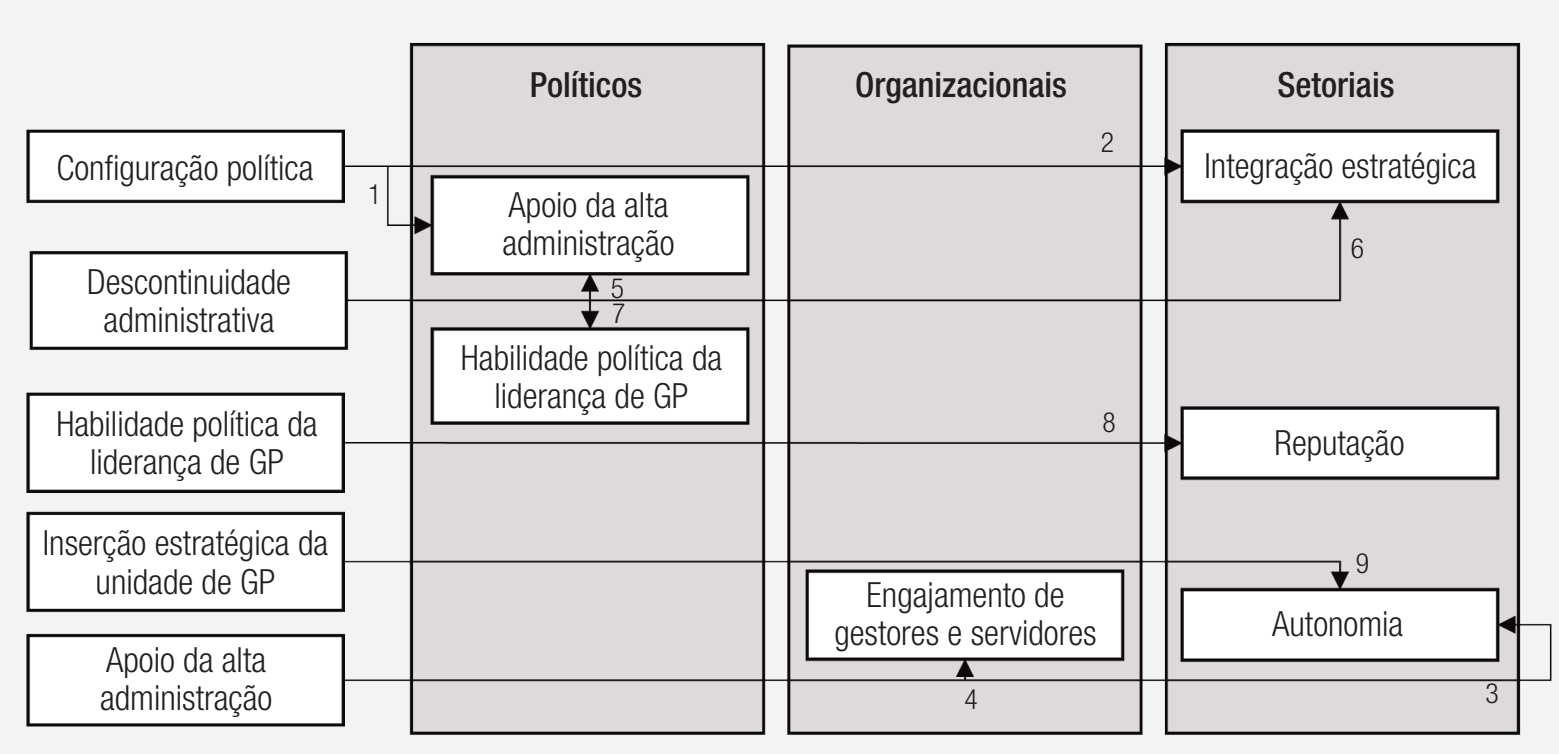

Fonte: Elaborada pelos autores.

Quanto à categoria organizacional, o aspecto mais presente nas falas dos participantes foram as características culturais, com menções referentes à dificuldade de mudar a cultura estabelecida devido a resistências e à tendência à acomodação por parte de gestores e servidores, às diferenças de valores entre gerações de servidores e aos resquícios dos valores patrimonialistas, com possíveis consequências para o engajamento de gestores e servidores (1) e, consequentemente, para o nível de integração estratégica da GP (2). Um exemplo são as tentativas realizadas, por uma das organizações pesquisadas, de implantação de um processo de avaliação de desempenho mais estruturado, vinculado aos objetivos organizacionais, que fracassaram justamente devido à resistência dos servidores. 
[...] nós criamos um modelo, desenvolvemos um sistema, aplicamos no departamento, e esse modelo simplesmente morreu [...] todo um esforço gigantesco de quase dois anos, de se tentar estruturar um modelo de RH na casa [...] e que foi vencido nem pela área política, pelas nossas resistências internas (Participante 5).

Tais achados são consentâneos com os resultados de outras pesquisas no setor público brasileiro, que identificaram entraves de cunho cultural ao alinhamento horizontal entre os subsistemas de GP, a exemplo de uma avaliação de desempenho meramente formal e simbólica, devido às resistências de servidores e gestores para participar (M. A. M. Lima \& I. V. Lima, 2013), e também a existência de características patrimonialistas como dificuldades na efetividade de modelos estratégicos de GP (Silva \& Mello, 2013).

O próximo aspecto, recursos organizacionais, constituiu-se de relatos sobre desequilíbrio na quantidade de cargos e funções, escassez de servidores, disponibilidade de sistemas informatizados e de recursos orçamentários e financeiros. Para os participantes, o elevado percentual de servidores comissionados, demissíveis sem motivação, pode significar maiores chances de descontinuidade em projetos de longo prazo (3), bem como dificuldades de engajamento dessa parcela do corpo funcional (4).

E aqui tem um complicador [...] provavelmente, né, nas casas legislativas, que é essa questão das categorias de servidor, a gente tem servidores efetivos e servidores não efetivos, né, os temporários, digamos assim, embora tenha temporário aí que tenha 20 anos de casa, mas assim, são temporários, mas isso cai também nessa questão da descontinuidade do negócio, né, então você, como é que você vai engajar um servidor que ele não se sente nem parte da instituição realmente (Participante 12).

Ademais, a crescente diminuição do número de servidores, sobretudo efetivos, pode resultar em equipes mais enxutas na unidade de GP, que ficaria com sua capacidade de trabalho reduzida e, consequentemente, teria menos tempo para questões estratégicas (5). Também houve menções à importância de estrutura de tecnologia da informação voltada a soluções de GP, com consequências positivas para a transparência dos processos e atividades da área (6). Por fim, foi citada como atual restrição a diminuição dos recursos disponibilizados para as atividades e os projetos de GP (7), o que poderia desacelerar o processo de implementação da vertente estratégica de GP e prejudicar a construção do vínculo entre a GP e o planejamento organizacional (Vo \& Bartram, 2012).

[...] a gente já tá prevendo pros próximos 5 anos, nós aqui da administração, né, um déficit de servidores que vai dar um caos daqui a 5 anos (Participante 10).

E a questão dos recursos financeiros e orçamentários, que hoje tá impactando muito nossa política, né, hoje a gente não pode fazer concurso, não pode fazer nada (Participante 9).

Quanto à estrutura organizacional, há um entendimento nas duas casas legislativas de que apresenta excesso de níveis hierárquicos e de divisões funcionais, o que a princípio poderia afetar negativamente a implementação da GEP (Fonseca \& Meneses, 2016), já que haveria dificuldade 
de atingir o alinhamento vertical de GP (8) e o envolvimento mais homogêneo no processo, com maior engajamento de gestores e servidores (9), bem como seria um cenário propício para um alto número de conflitos de interesse (10), o que impactaria as decisões da alta cúpula relativas às atividades de GP.

[...] falando da estrutura da casa, eu acho que [...] é bastante segmentada, eu acho como todo órgão público, né, isso é um dificultador pra você linkar a sua atividade com os objetivos estratégicos (Participante 11).

Ainda em relação à estrutura, um ponto positivo levantado é a existência de setores formalmente estabelecidos para o acompanhamento da execução do planejamento estratégico, com representantes inseridos nas unidades administrativas, incluídas as de GP, configuração esta que tende a auxiliar no alinhamento dos objetivos de GP com os organizacionais e na disseminação de uma cultura estratégica (11), semelhante ao exposto por Farndale, Paauwe e Boselie (2010).

[...] eu creio que a casa fez, eu acredito nisso, um trabalho ao criar [...] com toda a rede de assessoramento que é constituído pelos escritórios setoriais [...] ele começou a disseminar a cultura do planejamento, é, a cultura do alinhamento, da comunicação entre a direção e as áreas, as coordenações, então, ele trabalhou no sentido de que os objetivos estratégicos da instituição dessem, dessem certo (Participante 4).

$\mathrm{O}$ aspecto do engajamento de gestores e servidores foi visto como um desafio, no sentido de que há necessidade de maior participação gerencial no processo estratégico, de que existe um despreparo dos gestores intermediários, até em termos de habilidades políticas para lidar com o complexo cenário legislativo (12), e baixa participação dos servidores em geral, que tendem a resistir culturalmente às mudanças (13). Tal constatação implica a existência de restrições para integração de GP (14), já que esta depende também do alinhamento de gerentes de linha e da força de trabalho (Guest, 1987).

[...] nós trabalhamos num órgão político, né, então às vezes, para o gerente de linha tem que ter um bom técnico, uma formação, ter competência, mas tem que ter também habilidade pra lidar com os parlamentares, isso é um aspecto que a casa ainda tem deficiência (Participante 13).

Já a comunicação institucional foi abordada sob o enfoque da transparência na disponibilização externa e interna de informações. Segundo os participantes, propostas transparentes inibem a utilização de critérios diferentes dos técnicos pelas arenas decisórias (15), além de poderem facilitar a integração estratégica de GP (16), já que as informações sobre as atividades da área fluiriam mais facilmente pelos diversos setores da casa.

E, além disso, você tem a transparência, né, a transparência é a grande aliada das gestões, porque uma ação que, só pelo fato de você deixar ela transparecer, ela se purifica, digamos assim, né, ela já 
sai todos os lastros negativos que ela poderia ter num nível de decisão, e aí você consegue também direcionar a coisa pra forma ética, pra forma devida, pra forma honesta, pra forma limpa, pública, impessoal (Participante 8).

Autores como Lodge e Hood (2003) asseveram que ambientes que desencorajam o livre fluxo de ideias e críticas e têm restrições de comunicação e de compartilhamento de informações, podem estar relacionados à pouca sensibilidade ao ambiente externo e problemas de trabalho em equipe e dinâmicas intergrupos, fatores por eles identificados como possíveis causas da falha na implementação de modelos estratégicos de GP.

Como derradeiro aspecto de natureza organizacional se encontram as normas internas, cuja maior parte das recorrências se referiram à dificuldade de promover mudanças na GP que não necessitem de uma alteração na regulamentação interna existente ou até a elaboração de novas normas, o que, muitas vezes, pode desacelerar as inovações, já que, para modificações normativas, frequentemente as unidades de GP dependem de deliberações das instâncias superiores, o que reduz sua liberdade de ação (17).

[...] e você tem que, é... antes de qualquer coisa no serviço público, trabalhar a normatização desse, desse projeto, e depois a implementação das ações (Participante 7).

Contudo, alguns participantes entendem que a normatização interna de planos de ação das unidades de GP, após obtenção de apoio da instância adequada, poderia funcionar como um planejamento da mudança, além de ajudar a obter uma espécie de convencimento forçado dos atores e grupos envolvidos, mitigando possíveis barreiras políticas (18), semelhantemente ao que ocorreu na implementação da gestão estratégica na CD (Guimarães et al., 2012).

Eu já vi aqui a norma e a legislação como, assim, você normatizar aquilo que você quer, não como uma nova, não preexistente, você quer fazer alguma coisa então você normatiza, porque eu acho importante aqui [...] por exemplo, que é uma casa política, então eu acho importante normatizar, embora fiquem engessadas algumas coisas, mas pra você tentar seguir aquilo ali, já que a gente tá sempre obedecendo o princípio da legalidade, então se você normatiza as coisas, coloca ela certinho, como elas têm que ser feitas, eu acho que facilita a gente de cumprir e até de mostrar isso pro político (Participante 10).

De forma sintética e em consonância com a literatura contextual de GP (Hendry \& Pettigrew, 1990; Paauwe, 2004), em um cenário hipotético de adoção dos princípios da GEP no Legislativo Federal, as evidências demonstram que, possivelmente, a realidade organizacional seria em grande parte responsável pelas contingências com que se deparariam as unidades de GP, até por estas serem uma parte e um reflexo da organização, com impactos principalmente sobre os interesses considerados na configuração política, no nível de engajamento de gestores e servidores e na integração estratégica da GP (ver Figura 5). 


\section{FIGURA 5}

\section{MODELO TEÓRICO-EMPÍRICO DE INTERFERÊNCIAS EXERCIDAS PELOS ASPECTOS ORGANIZACIONAIS}

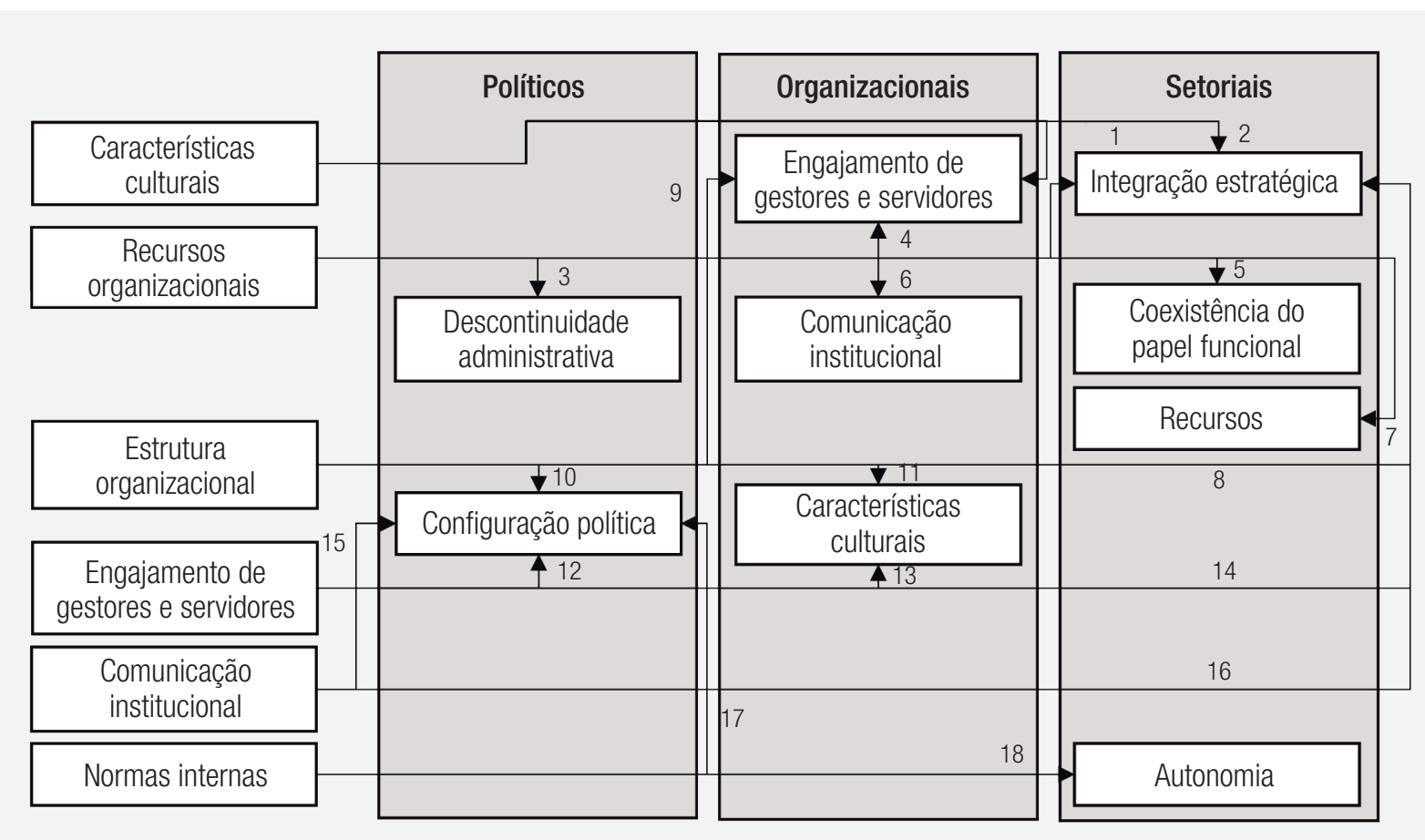

Fonte: Elaborada pelos autores.

$\mathrm{Na}$ categoria setorial, quanto ao aspecto integração estratégica de GP, os participantes entendem que há uma lacuna entre o que é estabelecido no planejamento estratégico e o que é realizado, de modo que várias atividades são desenvolvidas pelas unidades de GP sem nem constarem do plano, além dos objetivos traçados para a área não serem alcançados.

Eu não gosto, é chato ficar falando sobre os senões, né? Mas, entre isso aqui que foi feito e aquilo que a gente conseguiu colocar na prática [...] é... a gente nota que... um abismo é uma palavra grande, grande demais, né? Mas aí um vácuo, entre o que tem aqui e o que a gente realmente consegue colocar em prática, absorver, incorporar, internalizar (Participante 1).

Tal fato pode prejudicar a reputação do setor (1), já que há indícios de que esta é composta, por exemplo, pela percepção que os membros da alta gestão têm sobre o atendimento de suas expectativas, sendo que a cúpula tende a esperar justamente que a unidade de GP desenvolva atividades que ajudem a alcançar os objetivos organizacionais (I. G. L. Souza, 2016; Tsui \& Milkovich, 1987).

Acerca da reputação da unidade de GP, a maioria entendeu que as áreas de GP do Congresso Nacional padecem de problemas relacionados ao menosprezo e à falta de percepção da importância e de reconhecimento, frequentemente provenientes da cúpula política (2), com posterior disseminação para os demais níveis hierárquicos e servidores, o que prejudica a capacidade de atrair força de trabalho de outros setores e de reter a equipe que já possui (3), além de algumas vezes ocasionar a preterição das unidades de GP em decisões sobre alocação de recursos adotadas pela alta administração (4). 
É, e hoje, eu já ouvi de pessoas que "ah, pô, tava pensando em sair, dar uma reciclada, ir pra uma outra área", "ah, vamos pra gestão de pessoas", "não, menos a gestão de pessoas" [risos], "tudo menos lá", por quê? Porque já vê ali como uma área que tem muito trabalho, é muito cobrada, não é valorizada, e no final você ainda pode sair como uma pessoa que foi culpada de alguma coisa (Participante 14).

Relativamente ao aspecto recursos da unidade de GP, a já relatada escassez de servidores na organização também está refletida nas unidades de GP, pois há pouca força de trabalho e tendência de diminuição, causando morosidade no tratamento dos processos de GP e concentração da equipe nas atividades relativas ao papel funcional de GP (5), que devem ser priorizadas por questões legais e normativas. Outro aspecto indicado foi a experiência dos servidores que integram as unidades que, aliada às suas competências técnicas, podem ser fundamentais para que a transição para GEP seja efetiva (6) (Fonseca \& Meneses, 2016; Vo \& Bartram, 2012).

Não adianta você vir com "ah, vou instituir aqui, né, um gerenciamento de pessoas a coisa mais linda do mundo", não tem servidor, tem um fazendo aposentadoria, se ele sair, vai ser delivery, né, cada um vai lá e faz sua aposentadoria, então, eu tenho uma gestão de pessoas, é básico isso, então eu acho que isso é um fator preponderante, e negativo (Participante 9).

Em relação à autonomia da unidade de GP, é percebida como baixa pelos gestores de GP, uma vez que a área seria meramente propositiva, com limitada participação nas decisões que a envolvem e sem liberdade e independência para conduzir atividades relevantes, com possíveis restrições para o alinhamento vertical (7) e, consequentemente, para integração de GP (Fonseca et al., 2013; Vo \& Bartram, 2012).

[...] a unidade não tem força pra, pra, pra, pra decidir o que fazer [...] como a área [...] ela é propositiva, e ela não participa da movimentação de um servidor, ela não participa, né, dessas decisões que fazem com que a gestão de recursos humanos aconteça na prática, não tem muito como que a gente fazer alcançar (Participante 5).

Quanto ao aspecto estrutura da unidade de GP, há indícios de que o posicionamento hierárquico das unidades de GP da CD e do SF é vantajoso, já que se subordinam diretamente à Diretoria-Geral, órgão responsável pela maior parte das decisões administrativas das casas e pelo ordenamento de todas as despesas, o que pode indicar relativo grau de autonomia formal (8) (Fonseca, 2013). Outra questão estrutural é o fato de internamente a GP também ter sido indicada como excessivamente hierarquizada e segmentada, o que obstaculiza o alcance de maior integração entre suas subunidades e, logicamente, de maior alinhamento entre os subsistemas (9).

[...] isso influencia diretamente, em termos de estrutura hierárquica, vamos dizer assim, organograma se a gente for... ah, no caso da gestão de pessoas ela tá muito bem posicionada (Participante 6).

[...] essa segmentação que existe, então, mesmo dentro do setor, que já é menor, mas ele tem uma hierarquização, né, e muitas subdivisões, eu já busquei caminhar na linha de horizontalizar um pouco mais essa organização do departamento, né, porque eu acho, pra ver se faria, promovia essa maior interação entre os setores, tirar e quebrar essas paredes (Participante 1). 
O penúltimo aspecto setorial é a metodologia de implementação, a maior parte dos relatos considerou que a implementação da GEP no Legislativo Federal teria que ser contextualizada com a estratégia da organização e com as peculiaridades daquele ambiente, pois, em tentativas anteriores de se implementar modelos estratégicos de GP, a complexidade e a inadequação destes culminou em falta de efetividade e posterior abandono, ocasionado pela falta de engajamento dos servidores (10).

[...] eu diria assim, ele foi desenhado da forma que seria assim, o ótimo, que seria o ótimo, mas ele não foi pragmático [...] esbarrou em questões na casa que não foram superadas e não acredito que sejam superadas (Participante 7).

O aspecto setorial final é a coexistência do papel funcional de GP, referente ao excesso de tempo gasto com as atividades mais tradicionais e operacionais de GP, que fazem com que a área acabe direcionando menos esforços a um papel mais estratégico, o que pode ser um entrave ao alinhamento vertical (11). As possíveis interferências promovidas pelos aspectos da categoria setorial são representadas na Figura 6.

[...] se a gente fosse colocar aí um percentual, de um pra outro, eu acho que seria 60 pra parte de procedimentos e 40 pra parte estratégica, porque veja, você não pode dissociar uma coisa da outra (Participante 6).

\section{FIGURA 6 MODELO TEÓRICO-EMPÍRICO DE INTERFERÊNCIAS EXERCIDAS PELOS ASPECTOS SETORIAIS}

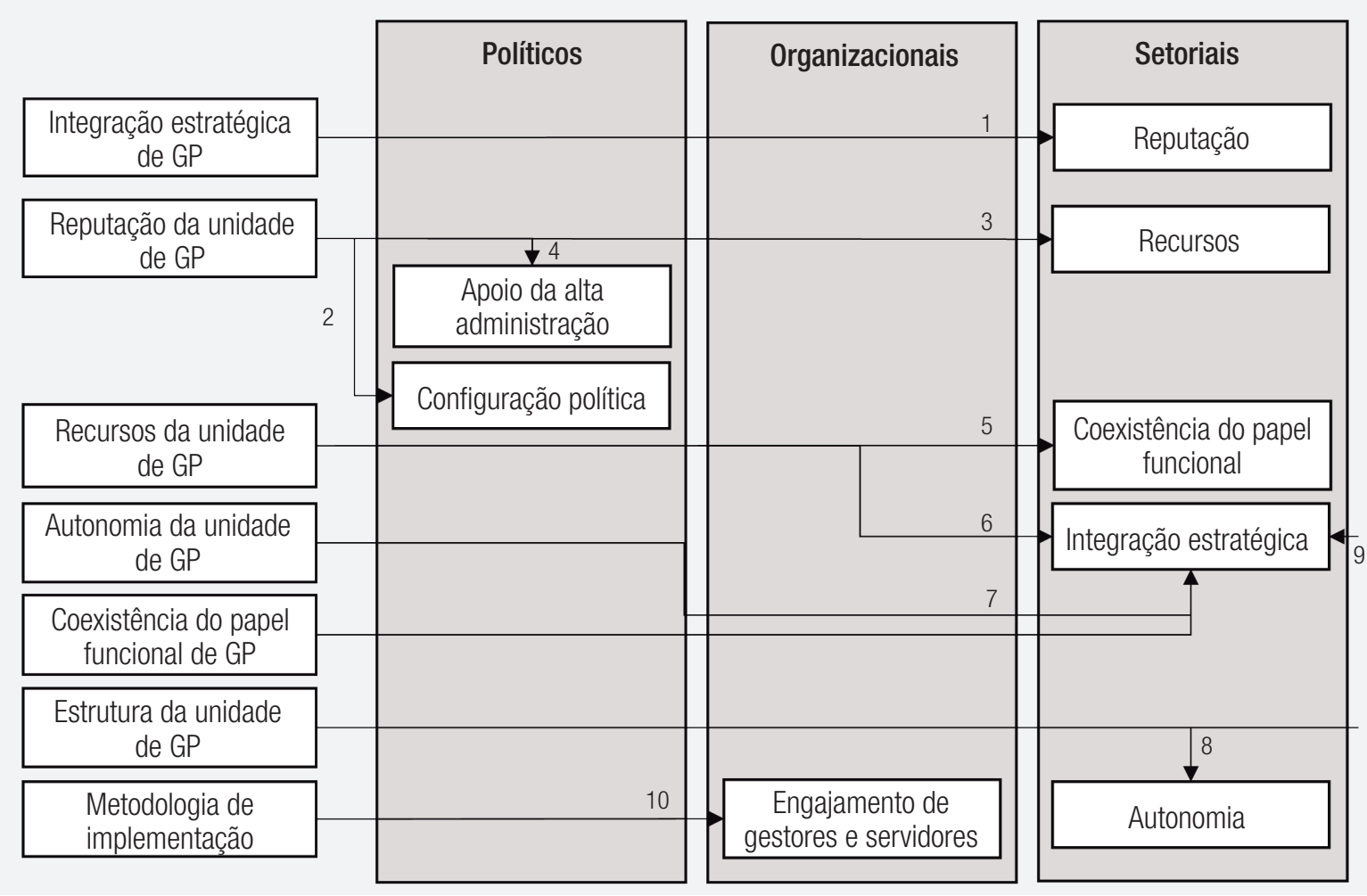

Fonte: Elaborada pelos autores. 
Diante disso, supõe-se que, apesar dos fatores setoriais serem resultantes das complexas relações entre os fatores institucionais, políticos e organizacionais, é possível que eles também influenciem o apoio da cúpula e a configuração política por meio da construção de uma reputação positiva com os grupos de interesse pertencentes às instâncias superiores e auxiliem em maior engajamento de gestores e servidores, desde que a metodologia de implementação seja condizente com a realidade organizacional.

Partindo de análise mais ampla e integrada do que foi abordado até aqui, sob o ponto de vista das categorias de aspectos, parece haver uma espécie de cadeia de relações, na qual o ambiente institucional influencia precipuamente o político (Fonseca et al., 2013; Fonseca \& Meneses, 2016; Iles, Almhedie, \& Baruch, 2012), em especial quanto à formação da agenda e ao condicionamento do processo decisório.

Esse processo decisório de natureza política, por sua vez, modela a realidade organizacional (Fonseca \& Meneses, 2016) e, consequentemente, setorial (Ingraham \& Rubaii-Barrett, 2007; Järvalt \& Randma-Liiv, 2010; Truss, 2008). Já o contexto organizacional condiciona os recursos e a estrutura detidos pela unidade de GP, bem como seu nível de integração estratégica (Camões \& Meneses, 2016; Farndale et al., 2010; Fonseca \& Meneses, 2016; Jacobson et al., 2014; Lodge \& Hood, 2003; RandmaLiiv \& Järvalt, 2011; Silva \& Mello, 2013; Teo, 2002; Vo \& Bartram, 2012).

Entretanto, assim como na proposta de Hendry e Pettigrew (1990) para uma GP contextualizada (Figura 1), nota-se a possível presença de um processo de retroalimentação em que a reputação da unidade de GP pode fazer com que as decisões sobre ela possam ser mudadas (I. G. L. Souza, 2016; Teo, 2002; Tsui, 1987; Tsui \& Milkovich, 1987), conforme o modelo hipotético simplificado apresentado na Figura 7.

\section{FIGURA 7 MODELO HIPOTÉTICO SIMPLIFICADO DE CADEIA DE RELAÇÕES ENTRE CATEGORIAS DE ASPECTOS}

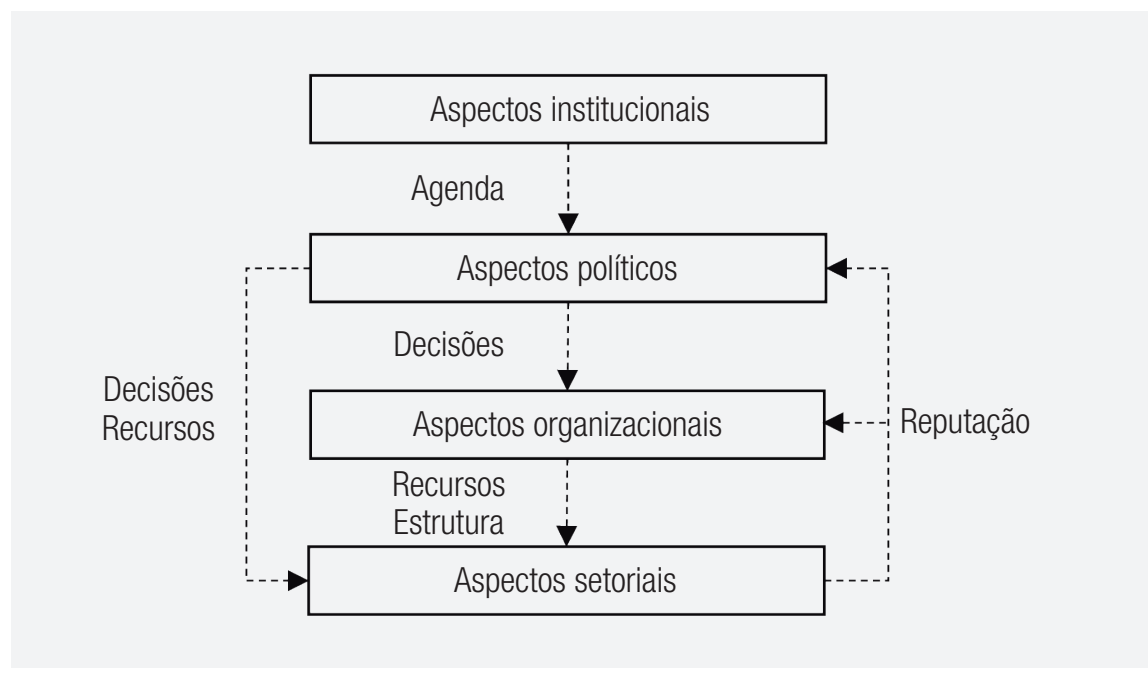

Fonte: Elaborada pelos autores. 
Diante do cenário esquadrinhado, supõe-se que talvez os fatores políticos sejam os mais sensíveis para a implementação da GEP nas casas legislativas, como já apontava a literatura (Cinnanti, 2011; Guimarães et al., 2015), pois são as decisões favoráveis a novas políticas e práticas de GP, por parte da alta administração, que possibilitam à área uma implementação bem-sucedida, o que se consubstancia em disponibilização de recursos e em autonomia para tanto, fatores já identificados por outros estudos como decisivos no setor público (Camões \& Meneses, 2016; Fonseca et al., 2013; Fonseca \& Meneses, 2016; Vo \& Bartram, 2012).

Ademais, dentre os aspectos políticos há dois que impactam diretamente o nível de integração estratégica de GP, princípio basilar da GEP (Guest, 1987): a configuração política, usualmente responsável por decisões de GP desalinhadas dos objetivos organizacionais; e a descontinuidade administrativa, que normalmente ocasiona a interrupção prematura de iniciativas de longo prazo conduzidas pela unidade de GP.

Infere-se, inclusive, que tanto os entraves mais relevantes, como já explanado, quanto as possibilidades de contorná-los, têm natureza política, já que, aparentemente, é por meio de habilidades políticas que os dirigentes das áreas de GP poderão bem atuar para alavancar sua reputação e angariar patrocínio da cúpula e, consequentemente, autonomia e recursos.

Enfim, com os resultados deste estudo, pôde-se compreender melhor o contexto a que está submetida a GP no Poder Legislativo Federal, com a constatação de que, possivelmente, a política seria um aspecto premente no caso da adoção dos princípios da GEP. Frise-se, no entanto, que as considerações ora tecidas, para terem melhor embasamento teórico-empírico, necessitam de aprofundamento investigativo sobre as relações e modelos propostos, bem como acerca dos efeitos da política na GP, já que tal interface constitui um tema ainda pouco estudado (Drory \& VigodaGadot, 2010).

\section{CONSIDERAÇÕES FINAIS}

Este estudo objetivou identificar os interferentes relativos à adoção dos princípios de GEP no Legislativo Federal brasileiro, bem como elaborar modelos teórico-empíricos e hipotético-dedutivos sobre as relações entre eles, constatando-se a suposta existência de 21 aspectos interferentes, divididos entre institucionais, políticos, organizacionais e setoriais, interligados por meio de 46 possíveis relações.

Com base nos achados e nos modelos propostos, inferiu-se que os aspectos políticos são, aparentemente, os que mais condicionam a e interferem na realidade da GP das casas legislativas federais brasileiras, de forma similar ao que já se propunha na literatura, sendo que esse tipo de aspecto também parece influenciar em grande medida os organizacionais e setoriais.

Academicamente, este estudo contribui para maior compreensão do contexto em que se insere a GP no Legislativo Federal brasileiro, tema ainda pouco explorado cientificamente (Araújo \& Silva, 2012). Do ponto de vista da prática, forneceu-se um diagnóstico sobre condicionantes contextuais que impactariam a adoção dos princípios da GEP, de modo que as organizações legislativas podem utilizar os resultados aqui constantes para o aprimoramento de suas políticas e práticas de GP e, consequentemente, de seus resultados, o que pode auxiliar a reversão do quadro em que o Legislativo figura como poder com pior avaliação junto à sociedade (Lamari, 2010).

No tocante às limitações, a pesquisa poderia ter se beneficiado de outros arcabouços teóricos, como a teoria institucional e a visão baseada em recursos, que proporcionariam maior riqueza de 
análise de dados e, consequentemente, de discussão dos resultados. Ademais, a amostra poderia ter sido composta por alguns dos atores e grupos de interesse com que as unidades de GP têm interface, de modo a complementar as opiniões dos gestores da área. Ressalte-se, por fim, que as categorias decorrentes do processo de análise de conteúdo e as propostas do quadro e dos modelos teóricoempíricos de relações entre aspectos poderiam ter passado por um processo de validação por juízes (profissionais e acadêmicos), de modo que os relacionamentos propostos pudessem ser aperfeiçoados.

Assim, estudos posteriores podem retomar o Legislativo como objeto de pesquisa e utilizar fundamentos teóricos diversos, com a formação de amostras que contenham indivíduos de diferentes unidades e posições hierárquicas dentro das organizações, talvez com foco mais detido nos aspectos políticos, aparentemente tão influentes nesse cenário.

Outrossim, futuras pesquisas poderão investigar mais detidamente cada um dos aspectos identificados, com possibilidade de proposição de definições constitutivas e operacionais. Também podem ser esquadrinhadas, testadas e validadas as prováveis associações entre aspectos interferentes identificados, com verificação de relações de mediação e de moderação.

Afinal, percebe-se que a realidade do Poder Legislativo Federal é complexa e influenciada por sua configuração política, o que talvez apresente aos gestores de GP desafios para promover mudanças e melhorias em suas práticas, cenário no qual habilidades e competências políticas talvez sejam relevantes para maior inserção e participação nas decisões que impactem a área. 


\section{REFERÊNCIAS}

Anselmi, L., Lazzini, S., \& Zarone, V. (2013). Institutional reform and public sector change: from knowledge and competence to accountable public management. Journal of US-China Public Administration, 10(9), 821-833.

Araújo, S. M. V. G., \& Silva, R. S. (2012). Reflexões e novas agendas de pesquisa para os estudos legislativos no Brasil. Revista Ibero-Americana de Estudos Legislativos, 2012(2), 58-74.

Armond, L. P., Côrtes, F. G., Santos, F. A. M., Demo, G., \& Meneses, P. P. M. (2016, Setembro). Gestão estratégica de pessoas: revisão da produção nacional de 2006 a 2015 e agenda de pesquisa para o contexto brasileiro. In Anais do $40^{\circ}$ Encontro da Associação Nacional dos Programas de Pós-Graduação em Administração. Mata de São João, BA.

Bardin, L. (2011). Análise de conteúdo. Lisboa, Portugal: Ed. 70.

Bergue, S. T. (2014). Gestão estratégica de pessoas no setor público. São Paulo, SP: Atlas.

Bonder, A., Bouchard, C.-D., \& Bellemare, G. (2011). Competency-based management: an integrated approach to human resource management in the Canadian public sector. Public Personnel Management, 40(1), 1-10.

Boyett, I., \& Currie, G. (2001). The failure of competence-based management education in the public sector: a problem of generic transfer or implementation? Personnel Review, 30(1), 42-60.

Brans, M., \& Hondeghem, A. (2005). Competency frameworks in the Belgian governments: causes, construction and contents. Public Administration, 83(4), 823-837.

Brown, K. (2004). Human resource management in the public sector. Public Management Review, 6(3), 303-309.

Camões, M. R. S. (2013). Análise do processo de implementação da Política Nacional de Desenvolvimento de Pessoal (Dissertação de Mestrado). Universidade de Brasília, Brasília, DF.

Camões, M. R. S., Fonseca, D. R., \& Porto, V. (2014). Apresentação. In M. R. S. Camões, D. R. Fonseca, \& V. Porto (Orgs.), Estudos em gestão de pessoas no serviço público (pp. 5-9). Brasília, DF: Escola Nacional de Administração Pública.
Camões, M. R. S., \& Meneses, P. P. M. (2016). Gestão de pessoas no governo federal: análise da implementação da política nacional de desenvolvimento de pessoal. Cadernos ENAP, 2016(45), 3-101.

Cascio, W. F. (2015). Strategic HRM: too important for an insular approach. Human Resource Management, 54(3), 423-426.

Cinnanti, C. J. J. (2011). A (des)confiança do cidadão no Poder Legislativo e a qualidade da democracia no Brasil. E-Legis, 2011(6), 84-95.

Cooper, D. R., \& Schindler, P. S. (2014). Business research methods. Nova York, NY: McGraw-Hill.

Creswell, J. W. (2014). Research design: qualitative, quantitative, and mixed method approaches. London, England: SAGE.

Daley, D. M., \& Vasu, M. L. (2005). Supervisory perceptions of the impact of public sector personnel practices on achievement of multiple goals. The American Review of Public Administration, 35(2), 157-167.

Delery, J. E., \& Doty, D. H. (1996). Modes of theorizing in strategic human resource management: tests of universalistic, contingency, and configurational performance predictions. Academy of Management Journal, 39(4), 802-835.

Drory, A., \& Vigoda-Gadot, E. (2010). Organizational politics and human resource management: a typology and the Israeli experience. Human Resource Management Review, 2010(20), 194-202.

Farndale, E., Paauwe, J., \& Boselie, P. (2010). An exploratory study of governance in the intra-firm human resources supply chain. Human Resource Management, 49(5), 849-868.

Farnham, D., \& Stevens, A. (2000). Developing and implementing competence-based recruitment and selection in a social services department: a case study of West Sussex county council. International Journal of Public Sector Management, 13(4), 369-382.

Flick, U. (2007). Designing qualitative research. London, England: SAGE.

Fonseca, D. R. (2013). Autonomia de unidades de gestão de pessoas para desempenho das atividades estratégicas de capacitação na Administração Pública Federal (Dissertação de Mestrado). Universidade de Brasília, Brasília, DF. 
Fonseca, D. R., \& Meneses, P. P. M. (2016). Fatores para implantação e desenvolvimento da gestão por competências em agências reguladoras federais. Revista Eletrônica Científica da UERGS, 2(2), 117-133.

Fonseca, D. R., Meneses, P. P. M., Silva, A. I., Filho, \& Campos, N. G. (2013). Autonomia para gestão estratégica de pessoas no setor público federal: perspectivas de análise e agenda de pesquisa. Revista de Administração Pública, 47(6), 1451-1475.

Guest, D. E. (1987). Human resource management and industrial relations. Journal of Management Studies, 24(5), 503-521.

Guimarães, A. S., Schwartz, F. P., Souza, J. W., Melo, M. R. M., \& Teixeira, R. V. (2012). Gestão estratégica no Poder Legislativo: o caso da Câmara dos Deputados. Revista do Serviço Público,63(1), 25-42.

Guimarães, A., Schwartz, F. P., Werneck, J. S., \& Melo, R. M. (2015). Strategic management in legislative public management: a comparative perspective. International Business and Management, 11(1), 13-24.

Hall, M., \& Holt, R. (2008). New public management and cultural change: the case of UK public sector project sponsors as leaders. In P. Windrum, \& P. Koch (Eds.), Innovation in public sector services: entrepreneurship, creativity and management (pp. 21-40). Bodmin, England: MPG.

Hammerschmid, G., \& Walle, S. V. (2011). The impact of the new public management: challenges for coordination and cohesion in European public sectors. Halduskultuur - Administrative Culture, 12(2), 190-209.

Harris, L. (2005). UK public sector reform and the "performance agenda" in UK local government. Personnel Review, 34(6), 681-696.

Hendry, C., \& Pettigrew, A. (1990). Human resource management: an agenda for the 1990s. The International Journal of Human Resource Management, 1(1), 17-43.

Hondeghem, A., Horton, S., \& Scheepers, S. (2006). Modelos de gestão por competências na Europa. Revista do Serviço Público, 57(2), 241-258.

Hood, C. (1991). A public management for all seasons? Public Administration, 1991(69), 3-19.
Iles, P., Almhedie, A., \& Baruch, Y. (2012). Managing HR in the Middle East: challenges in the public sector. Public Personnel Management, 41(3), 465-492.

Inácio, M., \& Rennó, L. (2009). Estudos legislativos no Brasil. In M. Inácio, \& L. Rennó (Org.), Legislativo brasileiro em perspectiva comparada (pp. 17-32). Belo Horizonte, MG: Ed. UFMG.

Ingraham, P. W., \& Rubaii-Barrett, N. (2007). Human resource management as a core dimension of public administration. Recuperado de https://faculty.cbpp. uaa.alaska.edu/afgjp/PADM601\%20Fall\%202009/ FPA-HRM-Article.pdf.

Jackson, S. E., Schuler, R. S., \& Jiang, K. (2014). An aspirational framework for strategic human resource management. The Academy of Management Annals, 8(1), 1-56.

Jacobson, W. S., Sowa, J. E., \& Lambright, K. T. (2014). Do human resource departments act as strategic partners? Strategic human capital management adoption by county governments. Review of Public Personnel Administration, 34(3), 289-301.

Järvalt, J., \& Randma-Liiv, T. (2010). Public sector HRM: the case of no central human resource strategy. Baltic Journal of Management, 5(2), 242-256.

Lacombe, B. M. B., \& Tonelli, M. J. (2001). O discurso e a prática: o que nos dizem os especialistas e o que nos mostram as práticas das empresas sobre os modelos de gestão de recursos humanos. Revista de Administração Contemporânea, 5(2), 157-174.

Lamari, R. (2010). Reforma do Legislativo. Cadernos Adenauer, 11(1), 38-50.

Leite, N. R. P., \& Albuquerque, L. G. (2011). Gestão estratégica de pessoas, comprometimento e contrato psicológico: o caso Vale. Revista de Administração da USP, 46(1), 19-31.

Lem, R. B. K. (2011). Evidence of strategic human resource management practice in a public sector organization: a content analysis of the HRM policy and strategy of the ministry of health of Ghana, 20072011. Health Policy And Development, 9(1), 7-16.

Lengnick-Hall, C. A., Beck, T. E., \& Lengnick-Hall, M. L. (2011). Developing a capacity for organizational resilience through strategic human resource management. Human Resource Management Review, 2011(21), 243-255. 
Lengnick-Hall, M. L., Lengnick-Hall, C. A., Andrade, L. S., \& Drake, B. (2009). Strategic human resource management: the evolution of the field. Strategic Human Resource Management, 2009(19), 64-85.

Lima, M. A. M., \& Lima, I. V. (2013). A gestão por competência e as funções de recursos humanos: estudo de caso na Universidade Federal do Ceará (UFC). Revista Ciências Administrativas, 19(2), 698-740.

Lodge, M., \& Hood, C. (2003). Competency and bureaucracy: diffusion, application and appropriate response? West European Politics, 26(3), 131-152.

Marler, J. H., \& Fisher, S. L. (2013). An evidencebased review of e-HRM and strategic human resource management. Human Resource Management Review, 2013(23), 18-36.

Mello, M. L. B. C., \& Amâncio, A., Filho. (2010). A gestão de recursos humanos em uma instituição pública brasileira de ciência e tecnologia em saúde: o caso Fiocruz. Revista de Administração Pública, 44(3), 613-636.

Mesch, D. J.; Perry, J. L.; \& Wise, L. R. (1995). Bureaucratic and strategic human resource management: an empirical comparison in the federal government. Journal of Public Administration Research and Theory, 5(4), 385-402.

Motta, P. R. M. (2013). O estado da arte da gestão pública. Revista de Administração de Empresas, 53(1), 82-90.

Paauwe, J. (2004). HRM and performance: achieving long term viability. New York, NY: Oxford University Press.

Peci, A., Pieranti, O. P., \& Rodrigues, S. (2008). Governança e new public management: convergências e contradições no contexto brasileiro. Organizações \& Sociedade, 15(46), 39-55.

Pichault, F. (2007). HRM-based reforms in public organizations: problems and perspectives. Human Resource Management Journal, 17(3), 265-282.

Randma-Liiv, T., \& Järvalt, J. (2011). Public personnel policies and problems in the new democracies of Central and Eastern Europe. Journal of Comparative Policy Analysis: Research and Practice, 13(1), 35-49.

Ring, P. S., \& Perry, J., L. (1985). Strategic management in public and private organizations: implications of distinctive contexts and constraints. Academy of Management Review, 10(2), 276-286.

Sheehan, C., Cieri, H., Cooper, B. K., \& Brooks, R. (2015). The impact of HR political skill in the HRM and organisational performance relationship. Australian Journal of Management, 41(1), 161-181.

Silva, F. M., \& Mello, S. P. T. (2013). A implantação da gestão por competências: práticas e resistências no setor público. Revista Eletrônica de Administração e Turismo, 2(1), 110-127.

Šiugždinienè, J. (2006). Competency management in the context of public management reform. Viešoji Politika Ir Administravimas, 2006(18), 26-33.

Souza, I. G. L. (2016). Reputação das áreas de recursos humanos (Dissertação de Mestrado). Universidade de Brasília, Brasília, DF.

Souza, R. L. S. (2004, noviembre). Gestão por competências no governo federal brasileiro: experiência recente e perspectivas. In Anales del 90 Congreso Internacional del CLAD sobre la Reforma del Estado y de la Administración Pública. Madrid, España.

Teixeira, H. J., Bassotti, I. M., \& Santos, T. S. (2013). Uma palavra dos organizadores. In H. J. Teixeira, I. M. Bassotti, \& T. S. Santos (Orgs.), Contribuições para a gestão de pessoas na administração pública (pp. 11-27). São Paulo, SP: Fundação Instituto de Administração \& Universidade de São Paulo.

Teo, S. T. T. (2002). Effectiveness of a corporate HR department in an Australian public-sector entity during commercialization and corporatization. The International Journal of Human Resource Management, 13(1), 89-105.

Terabe, C. P. A. R., \& Bergue, S. T. (2014). Gestão estratégica de pessoas como política pública: estudo de caso no Ministério da Ciência, Tecnologia e Inovação. In M. R. S. Camões, D. R. Fonseca, \& V. Porto (Orgs.), Estudos em gestão de pessoas no serviço público (pp. 11-37). Brasília, DF: Escola Nacional de Administração Pública.

Tran, B. (2015). Triangulation in organizational research:validating knowledge in human competence at work. In A. Takhar-Lail, \& A. Ghorbani (Eds.), Market research methodologies: multi-method and qualitative approaches (pp. 93-117). Hershey, PA: Business Science Reference. 
Truss, C. (2008). Continuity and change: the role of the HR Function in the modern public sector. Public Administration, 86(4), 1071-1088.

Tsui, A. S. (1987). Defining the activities and effectiveness of the human resource department: a multiple constituency approach. Human Resource Management, 26(1), 35-69.

Tsui, A. S., \& Milkovich, G. T, (1987). Personnel department activities: constituency perspectives and preferences. Personnel Psychology, 1987(40), 519-537.

Ubeda, C. L., \& Santos, F. C. A. (2008). Os principais desafios da gestão de competências humanas em um instituto público de pesquisa. Gestão \& Produção, 15(1), 189-199.

Vo, A., \& Bartram, T. (2012). The adoption, character and impact of strategic human resource management: a case study of two large metropolitan Vietnamese public hospitals. The International Journal of Human Resource Management, 23(18), 3758-3775.

Wright, P. M., \& McMahan, G. C. (1992). Theoretical perspectives for strategic human resource management. Journal of Management, 18(2), 295-320.

\section{Felipe Guimarães Côrtes}

https://orcid.org/0000-0001-9899-8080

Mestre em Administração pela Universidade de Brasília (UnB); Professor na Escola de Administração de Brasília do Instituto Brasiliense de Direito Público (EAB/IDP).E-mail: fgcortes@gmail.com

\section{Pedro Paulo Murce Meneses}

https://orcid.org/0000-0002-6937-3302

Doutor em Psicologia pela Universidade de Brasília (UnB); Professor no Programa de Pós-Graduação em Administração da Universidade de Brasília (PPGA/UnB). E-mail: pemeneses@yahoo.com.br 